\title{
Analysis of Non-Parametric Trend and Climatic Parameter Homogeneity Tests in a Data-scarce Region: A Spatio-Temporal Perspective in the Tawang River Basin, Eastern Himalayas
}

Juna Probha Devi ( $\square$ junapdevi@gmail.com )

Indian Institute of Technology Guwahati https://orcid.org/0000-0002-9897-0464

Chandan Mahanta

Indian Institute of Technology Guwahati

Anamika Barua

Indian Institute of Technology Guwahati

\section{Research Article}

Keywords: Climate changes, Precipitation, Homogeneity tests and non-parametric analyses, Eastern Himalayas

Posted Date: December 29th, 2021

DOI: https://doi.org/10.21203/rs.3.rs-1107455/v1

License: (c) (1) This work is licensed under a Creative Commons Attribution 4.0 International License.

Read Full License 
Analysis of Non-Parametric Trend and Climatic Parameter Homogeneity Tests in a Data-scarce Region: A Spatio-Temporal Perspective in the Tawang River Basin, Eastern Himalayas

Juna Probha Devi a*, Chandan Mahanta ${ }^{a, b}$ Anamika Barua ${ }^{a, c}$

${ }^{a}$ Centre for the Environment, Indian Institute of Technology Guwahati, Guwahati, Assam- 781039, India.

${ }^{\mathrm{b}}$ Department of Civil Engineering, Indian Institute of Technology Guwahati, Guwahati, Assam- 781039, India

${ }^{c}$ Department of Humanities and Social Sciences, Indian Institute of Technology Guwahati, Guwahati, Assam781039, India

(*junapdevi@gmail.com)

\section{Acknowledgements:}

The authors acknowledge the support given by the Central Water Commission Shillong and Itanagar for providing meteorological data; the Prediction of Worldwide Energy Resource (POWER) Project (ECMWF) NASA Earth Science/Applied Science Program and NASA Center for Climate Simulation for providing free data for the study. Authors also thankful to the Centre for the Environment- IIT Guwahati providing computational lab facility and MoE, Govt. of India for the financial assistance.

Abstract: This study is aimed at studying long-term historical and future (1950-2099) trends for the RCP 4.5 and RCP 8.5 on approximately 30-year timescale at annual and seasonal for precipitation and at annual, seasonal, monthly, and diurnal temperature range (DTR) for temperature maximum (T_max), temperature minimum (T_min) variations using statistical trend analysis techniques-Mann-Kendall test (MK) and Sen's slope estimator (S) and the homogeneity test using Pettitt's test. The study is carried out in three spatial points across the Tawang Chu in the district of Tawang, Arunachal Pradesh. The summer mean precipitation for RCP 4.5 (2006-2065) shows a positive trend with a rise in precipitation between $1.56 \mathrm{~mm}$ to $9.94 \mathrm{~mm}$ in all the study points. The mean annual precipitation statistics for all the points show an increase of RCP 4.5 in 2006-2052 and 2053-2099 timescale. Both RCP 4.5 and 8.5 scenarios exhibit a uniform rise in T_min and T_max during investigation. For all the points, the results likewise reveal a rising trend in mean annual T_min and T_max. Still, the inter-decadal temperature statistical analysis shows that the increase in mean annual T_min is greater than the increase in T_max, indicating a decreasing trend in DTR. It is anticipated that this study's outcomes will contribute to a better understanding of the relationship between change in climate and the regional hydrological behaviour and will be benefitting the society to develop a regional strategy for water resource management, can serve as a resource for climate impact research scope- assessments, adaptation, mitigation, and disaster management strategies for India's north-eastern region.

Keywords: Climate changes, Precipitation, Homogeneity tests and non-parametric analyses, Eastern Himalayas

\section{Introduction}

Outside of the polar zone, the Himalayas have the highest concentration of glaciers. These glaciers provide a source of fresh water for millions of people downstream in countries. There is clear evidence that due to climate change, In recent decades, the Himalayan glaciers have melted at an unprecedented rate, causing dramatic fluctuations in freshwater flow regimes (Gurung et al., 2011). The Himalayas (Pamir Plateau) are a massive mountain range that stretches 2500 kilometres east to west over several nations and encompassing about 67,028 glaciers with a total area of 1,20,162 $\mathrm{km}^{2}$ in Bhutan, Nepal, Pakistan, Afghanistan, China, and India (IPCC, 2014). The important features that define climate change are related to climate variables- precipitation and temperature. 
The elements of the two variables are increasing global temperature, cloud cover changes, abrupt changes in precipitation over land, seasonal variation in precipitation, and temperature patterns. The IPCC (2007) concluded that global temperature has been seen unequivocal warming trend since 1950. Multiple hydrological phenomena, as well as the availability of water, are altering in frequency and magnitude as greenhouse gas concentrations in the atmosphere increase (Bhave et al., 2016; Sharma and Goyal, 2020; Shivam et al., 2017a). According to the IPCC (2014), in the fifth assessment report (AR5), these ongoing warming trends are affecting the hydrology of the mountainous region leading to the occurrence of flash floods, drought, loss of life, and agricultural activities (Radinović and Ćurić, 2014; Sharma et al., 2011; Zhang et al., 2015). Significant impacts of warming trends will be on the snowpack and glaciers of the mountainous systems. With the increasing trend of air temperature across the globe, the Himalayan glaciers are retreating faster than normal (Scherler et al., 2011). Eventually, this will influence the regional hydrology and water resources. The relationship between global warming and anthropogenic activities is closely related to each other, threatening each other. Therefore, assessment and detection of the historical trend, changes, and variability; and futuristic projections became crucial for the regions at the regional and local level (Sharma et al., 2016; Shifteh Some'e et al., 2012).

To assess the historical trend of the climatic parameters, statistical analysis proved to be very useful. Application of numerous statistical tests, both parametric and non-parametric at global as well as in Indian region is found for trend analysis in hydro-meteorological series data, including both precipitation (Dash et al., 2013; Duhan and Pandey, 2013; Jain et al., 2013; Kumar et al., 2010; Milentijević et al., 2020; Shivam et al., 2018a; Yürekli, 2015) and temperature (Bapuji Rao et al., 2014; Kothawale et al., 2010; Liu et al., 2018; Shivam et al., 2017a). The rising number of studies on precipitation and temperature trend analysis in recent years, where the use of the nonparametric method, Mann-Kendall test, and Sen's slope estimator is extensively applied (Kousari et al., 2013; Li et al., 2018; Mahjabin and Abdul-Aziz, 2020; Malik et al., 2020; Milentijević et al., 2020; Mir et al., 2015).

Unlikely, various international and national studies on precipitation and temperature trends have been performed in mountain areas and projection using climate models; Eastern Himalayas (India) lack studies in the particular field at the spatial and temporal scales. Eastern Himalayas, covering the entire northeast part of India, are experiencing rising temperature and precipitation variables like maximum, minimum, mean, and prevailing ranges. Arunachal Pradesh, one of the major states falling in the eastern Himalayas, has glaciers and good seasonal snow cover at a higher elevation towards the northern part of the state inaccessible and has a minimal meteorological network. Due to changes in temperature and precipitation, this region is experiencing a change impact on the water resources. Only a few studies have been done in this region. Thus, the present study is aimed at studying long-term historical and future (1950-2099) annual and seasonal precipitation trend analysis, and temperature- temperature maximum (T_max), temperature minimum (T_min) variations- annual, seasonal, monthly, and diurnal temperature range (DTR) trend analysis using statistical trend analysis techniques- MannKendall test (MK) and Sen's slope estimator (S).

Further, the mean annual and monthly precipitation and T_min and T_max homogeneity test are done using Pettitt's test. It is anticipated that the findings of this study will aid in a better understanding of regional hydrological behavior as well as the link between climate change and the hydrological cycle. Formulating a regional water resources management strategy will be beneficial. It might provide data for climate impact research, such as monitoring, adaptation, mitigation, and disaster management plans for the northeast Indian region. 


\section{Materials and Methods}

\subsection{Study area}

The northern part of the Himalayan state, Arunachal Pradesh in India, is mostly covered with snow and glacier across the year. Tawang is one of the 23 districts in Arunachal Pradesh. The Tawang River (Chu) basin (shown in Fig. 1) with a downstream area of $2596.78 \mathrm{~km}^{2}$ covering the entire Tawang district of Arunachal Pradesh has been selected as the study area (a large part of the upstream Tawang chu basin falls in the Tibetan region). This basin in its upstream is covered by snow cover. The Tawang chu and Nyamjang chu are the two main rivers in the basin. The Tawang chu is the confluence of the Nyukcharong chu and Mago chu flowing from the eastern and north-eastern regions of the basin. This basin is a tourist attraction due to its snow-covered mountains and pass, scenic beauty, waterfall, and culture.

The entire basin extends between latitudes $27^{\circ} 27^{\prime} \mathrm{N}$ and $27^{\circ} 54^{\prime} \mathrm{N}$ and longitudes $91^{\circ} 33^{\prime} \mathrm{E}$ and $92^{\circ} 19^{\prime} \mathrm{E}$, lies on the west of the state of Arunachal Pradesh. The study area is shared by national and international boundaries, surrounded by Tibet in the North, Bhutan in the West, and West Kameng district in the South-East. The entire basin ranges over 979-6443 $\mathrm{m}$ above mean sea level (msl). The Tawang Chu basin experiences a monsoon climate, rainy or wet summers, and dry and cold winters. The monsoon season onsets at the end of May and continues till September or early October. The winter season is dominant in October, November, December, January, and February. The basin is found to be mountainous and mostly bare and uninhabited. Here, three location points given in Table 1 are used for the study. Point 1 is used for replicating the Central Water Commission data with the suitable ERA5-Land hourly reanalysis dataset, the Tropical Rainfall Measuring Mission (TRMM), and the Global Precipitation Measurement (GPM) for precipitation; and the ERA5-Land hourly reanalysis dataset for temperature maximum (T_max) and temperature minimum (T_min).

\subsection{Data source}

\subsubsection{Central Water Commission (CWC) India Dataset}

In this analysis, the Central Water Commission (CWC) meteorological data- precipitation and temperature (maximum and minimum) ground station data has been utilized. The study area in its downstream has several gauge stations with varied data collection start periods, and the nearest gauge CWC station discharge site- Muruga Bridge site (Lat $27^{\circ} 37^{\prime} 4.8^{\prime \prime}$ and Long $92^{\circ} 0^{\prime} 28.8^{\prime \prime}$ ) is used for the study location near the basin outlet. The daily temperature and precipitation CWC dataset for the station are available from March 2017 to December 2018 and used in the study.

\subsubsection{Climate Dataset}

The climatic data (air temperature-maximum and minimum) for the current study were collected from the NASA POWER (Prediction of Worldwide Energy Resources) project since ground data was insufficient for selecting a General Circulation Model (GCM) for trend analysis. The data for the POWER project comes from NASA's World Climate Research Program (WCRP), Global Energy and Water Cycle Experiment (GEWEX), Surface Radiation Budget Project (NASA GEWEX SRB), and Clouds and the Earth's Radiant Energy System (CERES) projects at NASA LaRC, as well as the Goddard Space Flight Center's Global Modeling and Assimilation Office (https://power.larc.nasa.gov). The ERA5-Land hourly data from the European Centre for Medium-Range Weather Forecasts (ECMWF), the Tropical Rainfall Measuring Mission (TRMM) and the IMERG data from Global Precipitation Measurement (GPM), the global successor to TRMM data has been also used to imitate as the ground 
data for precipitation. The ERA5-Land hourly- a reanalysis dataset, comprises both temperature and precipitation datasets. The land component of the ECMWF ERA5 climate reanalysis has been replayed to create ERA5-Land. Reanalysis assimilates data from the model and observations from all across the world to create a global dataset that is both complete and consistent (Muñoz, 2019). The ERA5-Land hourly data is gridded from 1 January 1981 to 31 December 2019 with $0.1^{\circ} \mathrm{x} 0.1^{\circ}$ spatial resolution in Network Common Data Form (NetCDF) format. The TRMM is a NASA-JAXA collaborative project that was launched in 1997 to research tropical rainfall. TMPA (TRMM) data, which were used for this investigation, have a spatial resolution of 0.250 .25 with a coverage range of $50 \mathrm{~N}-50 \mathrm{~N}$, and are accessible on a monthly basis. The latest version of the IMERG-GPM final-run product V06, released in April 2014, are also utilised. This product has a spatial resolution of $0.1 \circ \times 0.1 \circ$ and a coverage of $60 \circ \mathrm{N}-60^{\circ} \mathrm{N}$ (https://disc.gsfc.nasa.gov/datasets).

\subsubsection{GCM- NASA Earth Exchange Global Daily Downscaled Projections (NEX-GDDP) dataset}

The NEX-GDDP (General Circulation Model (GCM) carried out with the Coupled Model Intercomparison Project Phase 5 (CMIP5)) dataset that consists of global downscaled climate scenarios has been used. These datasets are developed supporting the Intergovernmental Panel on Climate Change (IPCC) Fifth Assessment Report (AR5). It contains two scenarios: scenario RCP 4.5 and scenario RCP 8.5 from the four Representative Concentration Pathways scenarios for greenhouse gas emissions (RCPs) with $0.25^{\circ} \mathrm{x} 0.25^{\circ}$ of spatial resolution (Melton, 2015). Daily precipitation, maximum temperature, and minimum temperature are included in each of the climatic projections for the period from 1950-2005 as a retrospective run and from 2006-2099 as a Prospective run (https://www.nccs.nasa.gov/services/data-collections/land-based-products/nex-gddp).

\subsection{Methodology}

\subsubsection{Validation process}

Data scarcity is one of the main problems in study areas with high mountain regions. Our study area has very few data stations. For analysis or any validation process, relatively large ground data is valuable. Therefore, to meet the said demand, the small temporal scale CWC data of 2017-2018 meteorological data has been validated with the ERA5-Land hourly reanalysis dataset, the Tropical Rainfall Measuring Mission (TRMM) dataset, and the Global Precipitation Measurement (GPM) dataset for precipitation; and the NASA POWER along with the ERA5Land hourly reanalysis dataset for T_max and T_min. The statistical validation has been done using Pearson's Correlation coefficient (r) and Bias, resulting with $r$ value- 0.91, 0.90, 0.86 and 0.88; and Bias value of -14.72, 19.05, -10.34 and 34.93 for the ERA5, GPM, TRMM and NASA POWER precipitation datasets respectively. Likewise, the CWC- T_max and T_min data is also validated with the ERA5-Land hourly reanalysis and the NASA POWER dataset for T_max and T_min using the same statistical method and resulted for T_max ' $r$ ' value0.80 and 0.79, Bias value 7.83 and 2.40; and T_min ' $r$ ' value- 0.88 and 0.87 , Bias value 10.23 and 4.99 , respectively. From the statistical validation of CWC datasets with the ERA5 hourly, GPM, TRMM data and NASA POWER data, the NASA POWER T_max and T_min and ERA5 precipitation is justifiable and can be replicated with the CWC dataset.

The second step considered for the study is validating the NASA POWER and ERA5 data with the NEX-GDDP dataset and selecting the GCM models that are suitable to the study area. The NEX-GDDP historical data for the year 1998-2005 of 11 GCMs, as shown in Table 2, has been used to validate an assortment of the suitable GCM 
for the trend analysis. The agreement and the bias between the NASA POWER and the NEX-GDDP GCM data for T_max and T_min; and the ERA5 and the NEX-GDDP GCM data performances have been evaluated and compared using few selected statistical methods- Bias (\%), Pearson's Correlation coefficient (r), Root Mean Square Error (RMSE), and Mean Absolute Error (MAE) (Kanda et al., 2020; Tang et al., 2020; Zhang et al., 2020) as shown in Table 3. These statistical methods are used for the ranking of the best GCM to be used for further steps in the study. The weighted sum model is used to rank the GCM models. The two GCMs- GFDL-CM3 and CSIRO-Mk3-6-0 are ranked 1 for temperature and precipitation, respectively, and used in the trend analysis study. The final step in the study, i.e., The Mann-Kendall (MK) test, and Sen's slope estimator are used to analyse trends in the data.

\section{Ranking the datasets}

The weighted sum model (WSM)- a multiple criteria decision making (MCDM) approach has been used for ranking the GCMs validated with ERA5. The WSM or simple additive weighting (SAW) (eq.1) is one of the simplest and most commonly used MCDM techniques (Kolios et al., 2016; Mulliner et al., 2016; Triantaphyllou, 2000) combines the criteria values for each alternative and applies the individual criteria weights.

$$
A_{W S M}^{*}=\max \sum_{i}^{m} a_{i j} w_{j}
$$

where $i=1, \ldots, m, A^{*}{ }_{W S M}$ denotes the weighted sum score, $a_{i j}$ denotes the score of the $i$-th option in relation to the $j$-th criterion, and $\mathrm{w}_{\mathrm{j}}$ is the weight of the $j$-th criterion.

\subsubsection{Mann-Kendall Trend Detection:}

The precipitation and temperature trend tests are done using the Mann-Kendall (MK) test (Kendall 1975; Mann 1945), a non-parametric statistical test identifying monotonic increasing or decreasing trends. This method is extensively used in climatic variable trend analysis and to know the existence of a trend in the climatic variables (Milentijević et al., 2020; Mir et al., 2015; Sharma and Goyal, 2020; Sharma et al., 2016; Shivam et al., 2018b). If the Mann-Kendall Z-value is larger than +1.96 for a significance threshold of 0.05 , the test shows a significantly rising (positive) trend. If the Z-value is calculated lower than -1.96 , the test shows a declining (negative) trend. The test's null hypothesis (H0) says that there is no trend in the series. The alternate hypothesis (Ha) signifies the presence of an increasing or decreasing trend in the temporal data series. The magnitude of the trend or shift throughout the study is determined using Sen's slope estimator. Here, the MK test is used for historical and futuristic time series analysis of precipitation and temperature trends. The definition of MK statistics (S) is as follows eq.2:

$$
S=\sum_{i=1}^{N-1} \sum_{j=i+1}^{N} \operatorname{sgn}\left(x_{j}-x_{i}\right)
$$

where $N$ is the number of data points, assuming $\left(x_{j}-x_{i}\right)=\theta$, the value of $\operatorname{sgn}(\theta)$ (eq.3) is computed as follows:

$$
\operatorname{sgn}(\theta)=\left\{\begin{array}{c}
1 \quad \text { if } \theta>1 \\
0 \quad \text { if } \theta=1 \\
-1 \quad \text { if } \theta<1
\end{array}\right.
$$

For all the differences evaluated, this statistic indicates the number of positive variations minus the number of negative variations. The statistic S's (eq.4) variance is computed as follows: 


$$
\operatorname{Var}(S)=\left\{N(N-1)(2 N+5)-\sum_{k=1}^{n} t_{k}\left(t_{k}-1\right)\left(2 t_{k}+5\right)\right\} / 18
$$

where $\mathrm{N}$ represents the total number of data points in the data series, $\mathrm{n}$ represents the number of tied groups in the set of data, and $t_{k}$ represents the number of tied groups in the $\mathrm{k}^{\text {th }}$ tied group, respectively. The "Z-statistic" of Mann-Kendall is calculated as follows in eq.5:

$$
Z=\left\{\begin{array}{cc}
\frac{S-1}{\sqrt{\operatorname{Var}(S)}} & \text { if } S>0 \\
0 & \text { if } S=0 \\
\frac{S+1}{\sqrt{\operatorname{Var}(S)}} & \text { if } S<0
\end{array}\right.
$$

The null hypothesis of no trend is accepted or rejected at a 95 percent confidence interval depending on the Zstatistics value.

\section{Sen's Slope Estimator}

Sen's slope estimator (eq.6) is a non-parametric approach for determining the amplitude of a trend in a time series (Sen 1968). The Sen's slope may be computed using the following formula:

$$
T_{i}=\frac{x_{j}-x_{k}}{j-k} \text { for } i=1,2,3, \ldots \ldots N
$$

where $x_{j}$ and $x_{k}$ are data values at time $j$ and $k$, respectively; Sen's estimate of slope $(\beta)$ is the median of these $N$ values of $\mathrm{T}_{\mathrm{i}}$. A positive value indicates an increasing trend in the time series, whereas a negative value suggests a downward trend.

\section{Homogeneity test using Pettitt's test:}

A test for change point detection is a crucial strategy for determining when a major shift in a time series of variables occurred. Inhomogeneity in time series can lead to erroneous interpretations of exceptional occurrences and can be deceiving when interpreting time-series tendencies. Significant fluctuations in the mean are a common existence in time series data due to inhomogeneity. The Pettitt's test (Pettitt, 1979) is a non-parametric test that does not make any assumptions about data distribution and is commonly employed in continuous data hydrological or climatic series to detect any significant change in the data series (Chakraborty et al., 2017; Ilori and Ajayi, 2020; Kocsis et al., 2020; Liu et al., 2012). It compares the null hypothesis $\left(\mathrm{H}_{0}\right)$ where the T variables follow one or more distributions with the same location parameter is compared to the alternative hypothesis $\left(\mathrm{H}_{\mathrm{a}}\right)$, which depicts the existence of a change point. The Pettitt's test for change point $\left(K_{T}\right)$ (eq.7) statistics is described as-

$$
K_{T}=\max \left|U_{t, T}\right|
$$

where,

$$
U_{t, T}=\sum_{i=1}^{t} \sum_{j=t+1}^{T} \operatorname{sgn}\left(X_{i}-X_{j}\right)
$$

The statistic $K_{T}$ is significant at probability approximated for $\mathrm{p} \leq 0.05$. 


\section{Results and Discussion}

\subsection{Validation of GCMs}

For the three study points- point 1, point 2 , and point 3 in the Tawang basin, the statistical method of validation and ranking of GCMs using the weighted sum model resulted in the selection of the two most suitable GCMsGFDL-CM3 and CSIRO-Mk3-6-0 for temperature and precipitation data for further trend analysis, respectively. A boxplot is used to comprehend and evaluate the distribution and variability of datasets on a temporal scale as well as for various RCP scenarios. Temperature and precipitation datasets are divided into three categories: historical (1950-1977 and 1978-2005), RCP 4.5 scenario (2006-2035, 2036-2065, and 2066-2099), and RCP 8.5 scenario (2006-2035, 2036-2065, and 2066-2099). (2006-2035, 2036-2065 and 2066-2099). The boxplots of points 1, 2, and 3 for precipitation on a historical and futuristic scale of approximately 30 years are shown in Fig. 2. In both the historic and RCP scenarios, the plot distribution reveals an overall growing trend in the mean and a broad range of variation in the lower and upper ranges of the datasets.

In contrast to scenario RCP 8.5 for 2066-2099, scenario RCP 4.5 for 2066-2099 shows an increasing upper and lower precipitation limit at all study locations. Fig. 3 shows the boxplots of points 1, 2, and 3 for T_min and T_max on a historical and futuristic scale of around 30 years, skewed in character. The plot distribution for $\mathrm{T} \_$min in both the historic and RCP scenarios demonstrates an overall rising trend in the mean in both the lower and upper ranges of the datasets. The RCP 8.5 scenario for 2066-2099 shows a rise in the upper and lower limits of T_min at all study locations in the boxplot. Also, T_max at points 2 and 3 shows a similar temperature distribution pattern, with the mean steadily increasing and the minimum and maximum temperature limits for the T_max increasing. At point 1, a huge difference is observed between the historic 1978-2005 and RCP 2006-2035, which later shows a dramatic increase of $11.29^{\circ} \mathrm{C}$ and $11.24^{\circ} \mathrm{C}$ in the lower and upper limits T_max, respectively.

\subsection{Precipitation trend analysis}

Fig. 4 shows the Mann-Kendall trend test results applied on mean annual and seasonal precipitation on a temporal scale using the GCM- CSIRO-Mk3-6-0 for the three selected study points. The three study points- point 1, point 2 , and point 3 are studied on an annual scale and seasonal scale (winter, summer, monsoon, and post-monsoon) for the temporal scale- historical (1950-1977 and 1978-2005), RCP 4.5 scenario (2006-2035, 2036-2065, and 2066-2099), and RCP 8.5 scenario (2006-2035, 2036-2065, and 2066-2099).

At all the temporal scales and spatial scales, there is no significant trend found. Only at study point 3 with RCP 4.5 for the mean annual precipitation in the intra-decadal time scale 2066-2099, a significant declining trend was observed at a 95\% confidence level. Table 4 also shows Sen's slope magnitude of precipitation (annual) in all the basins. The maximum precipitation increase can be seen in all the study points as $9.14 \mathrm{~mm}, 0.08 \mathrm{~mm}, 9.94 \mathrm{~mm}$, $2.34 \mathrm{~mm}$, and $3.19 \mathrm{~mm}$ for the annual, winter, summer, and post-summer, respectively. The maximum precipitation decrease is as low as $-22.15 \mathrm{~mm}$ (annual precipitation) at study point 2 for the time scale 2066-2099 at scenario RCP 4.5 .

Fig. 5 shows the trend test for the monthly precipitation at all three study points. There is a marked increasing trend observed in few months for the various time scale- RCP 4.5 April (2036-2065) and October (2066-2095) and a decreasing trend in August (2006-2035), June, and November (2066-2095) at point 1. A similar trend is also observed in the other 2 points for the same months. Across the months of a year, the maximum increase and 
maximum decrease in the magnitude of precipitation for study points 1,2, and 3 are found in April and August $3.40 \mathrm{~mm}$ and $-7.90 \mathrm{~mm} ; 4.36 \mathrm{~mm}$ and $-10.73 \mathrm{~mm} ; 3.86 \mathrm{~mm}$ and $-9.04 \mathrm{~mm}$, respectively, as shown in Table 5 .

\subsection{Temperature trend analysis}

\subsubsection{Mean maximum temperature (T_max)}

Fig. 6(a) shows the trend in all the study points for mean T_max for all the seasons. At all the study points, the historic mean T_max has shown a negative trend, but a positive trend observed for the RCP scenarios at all the timescale. There is an overall increase in the annual, monsoon, and post-monsoon mean T_max at all the points, with the RCP 8.5 scenario being the highest trend for T_max at all the seasons. The mean T_max positive trend can be seen in both the RCP 8.5 at all the seasons, the highest trend in the monsoon season at the intra-decadal (2066-2099).

At all the study points, for the RCP 8.5, the winter season is also showing a positive trend. The magnitude of increasing or decreasing in the mean annual and seasonal T_max is shown in Table 6, where it can be observed that there is a maximum rise in T_max is seen in the mean monsoon and post-monsoon season at study point 1 for RCP 8.5; and annual mean T_max, winter mean T_max and summer mean T_max at study point 2 for RCP 8.5-2066-2099. A maximum mean T_max is observed as $0.161^{\circ} \mathrm{C}$ in study point 2 , and the minimum mean T_max is observed as $-0.060^{\circ} \mathrm{C}$ at study points 1 and 2 .

Similarly, the trend test for mean monthly T_max in Fig. 7(a) is observed to increase positively for all the months and time scale at all the study points. The historical (1950-1977) mean monthly T_max is observed to have a negative trend at all the study points for January, July, August, and September. Apart from historical (1950-1977), all other study points with change in RCPs and time scale observed a significant positive trend, a maximum trend observed in all the months except February, March, and April in the RCP 4.5 scenario. The T_max magnitude in Table 7 also shows a maximum rise in mean monthly T_max for all the months, the maximum rise in April$0.196^{\circ} \mathrm{C}$ (RCP $\left.8.52066-2099\right)$, and maximum fall in April at $-0.023{ }^{\circ} \mathrm{C}$ (RCP $4.52036-2065$ ) in study point 1. Likewise, in study points 2 and 3, maximum rise and fall of mean T_max is observed in April- $0.184^{\circ} \mathrm{C}(\mathrm{RCP} 8.5$ 2066-2099), $0.168^{\circ} \mathrm{C}(\mathrm{RCP} 8.52066-2099)$, and $-0.027^{\circ} \mathrm{C}(\mathrm{RCP} 4.52036-2065)$, and $-0.030^{\circ} \mathrm{C}$ (RCP $4.52036-$ 2065), respectively.

\subsubsection{Mean minimum temperature $\left(T_{-}\right.$min)}

Similar to mean annual and seasonal T_max, the trend test for T_min also shows a significant negative trend in the historical time scale for both the RCPs at all the study points, as shown in Fig. 6 (b). A significant positive trend is observed in both annual and seasonal scale at all the study points for the two RCPs- RCP 4.5 and RCP 8.5 , the latter showed the maximum positive trend at three intra-decadal time scale. The annual scale has shown a maximum positive trend in T_min for both the RCPs at all the time scale. The highest $\mathrm{Z}$ value of 0.738 is observed at study point 1 in the annual scale at the RCP 4.5 scenarios. The RCP 8.5 has shown a significant positive trend among all the study points for all the seasons- summer $(Z=0.747)$, monsoon $(Z=0.834)$, and post-monsoon $(\mathrm{Z}=0.651)$, winter maximum positive $\mathrm{T}_{-}$min trend is observed at study point 2 for RCP 4.5. The maximum negative trend in T_min is observed in the historic scale at all study points - maximum lowest negative is as follows: -0.222 at study point 1 . Table 9 shows the maximum magnitude ranges between $0.138^{\circ} \mathrm{C}$ at study point 2 and $0.073^{\circ} \mathrm{C}$ at study point 1 in the mean annual and seasonal T_min for the RCP 8.5 summer season and RCP 
4.5 monsoon season, respectively. The minimum decrease in $\mathrm{T} \_$min is between $-0.031^{\circ} \mathrm{C}$ and $-0.010^{\circ} \mathrm{C}$ for the post-monsoon (historical) at study point 2 and summer season (historical) at study point 1, respectively.

For the mean monthly T_min, Fig. 7(b) shows a significant positive trend for all the twelve months at each study point, especially for May-December in both the RCP scenarios. The mean monthly T_min with the maximum positive trend is observed for RCP 8.5 as 0.710 for September at study point 1 and 0.706 for June and September at study points 2 and 3, respectively. The maximum negative range for the minimum monthly T_min is observed as $-0.238,-0.233$, and -0.249 at all the study points for the historical time scale. Table 8 clearly shows the magnitude rise and fall of the mean monthly T_min in the study points. The maximum rise in the mean monthly T_min is observed in RCP 8.5 as $0.144^{\circ} \mathrm{C}$ March month at the study point $1,0.138^{\circ} \mathrm{C}$ December month at study point 2, and $0.135^{\circ} \mathrm{C}$ December month at the study point 3. Similarly, the maximum fall in mean monthly T_min is observed in historic timescale as $-0.058^{\circ} \mathrm{C}$ January at study point $1,-0.052^{\circ} \mathrm{C}$ October at study point 2 , and $0.051^{\circ} \mathrm{C}$ January at study point 3 .

\subsubsection{Mean monthly Diurnal Temperature Range (DTR)}

Table 10 shows the trend test for the Diurnal temperature range for the two RCP scenarios at all the study points. The DTR is calculated by subtracting minimum daily temperature from the maximum daily temperature data for RCP 4.5 and RCP 8.5 scenarios at each point. From the Table 10, both significant positive and significant negative trend is observed. The negative maximum mean monthly DTR Z value falls to -0.499 (June) at study point 2 for RCP 4.5 scenario and a significant positive trend of $\mathrm{Z}$ value $=0.366$ (April) at study point 1 for RCP 8.5 scenario. The maximum magnitude rise and maximum fall in mean monthly DTR are different in all the study points. A maximum rise in mean monthly DTR at all the study points 1,2 , and 3 are $-0.057^{\circ} \mathrm{C}$ (April, RCP 8.5=2066-2099), $0.076^{\circ} \mathrm{C}$ (February, RCP 4.5=2036-2065) and $0.062^{\circ} \mathrm{C}$ (April, RCP 8.5=2066-2099), respectively. Similarly, the maximum fall in mean monthly DTR at all the study points falls for both the RCP 8.5 and RCP 4.5 scenarios: $0.055^{\circ} \mathrm{C}$ (December, RCP 8.5 $=2036-2065$ ), $-0.079^{\circ} \mathrm{C}$ (December, RCP $4.5=2066-2099$ ) and $-0.066^{\circ} \mathrm{C}$ (December, RCP 8.5=2066-2099) at study point 1, 2, and 3, respectively.

\subsection{Homogeneity test using Pettitt's test}

The homogeneity test using Pettitt's test on mean annual and monthly precipitation, T_min, and T_max is done for the three study points in the Tawang river basin. The change point of the year is made on three-time scales: historical (1950-2005), RCP 4.5 (2006-2099), and RCP 8.5 (2006-2099). The RCP scenarios are further divided into near-future (2006-2052) and distant future (2053-2099). The statistically significant Pettitt's test result is given in Table 11, which shows the change point year and shift direction in the continuous time-series datasets. A negative change in precipitation is likely to be observed in the historical time scale at study points 1 and 2 for October (1988). This decline in precipitation is observed in the (District Statistical Handbook of Tawang, Arunachal Pradesh 1989, 1989), where a sudden decline of precipitation can be noticed in October (1988). The RCP 4.5 and RCP 8.5 have also indicated an increasing precipitation pattern for April, August, and October and a decline in the pattern for January (RCP 8.5- 2038) and July (RCP 4.5-2020), mostly observed in study point 1. Annual precipitation increasing change point is only likely to be observed for RCP 8.5 from the year 2065, from an annual mean of $1490 \mathrm{~mm}(1.6 \%)$ to $1902 \mathrm{~mm}(29.7 \%), 1996 \mathrm{~mm}(0.9 \%)$ to $2588 \mathrm{~mm}(30.8 \%)$, and $1622 \mathrm{~mm}$ $(1 \%)$ to $2071 \mathrm{~mm}(29 \%)$ percent increase from historic precipitation for study points 1, 2 and 3, respectively. 
Unlike precipitation, the change point year in the mean T_min and T_max is observed in all the months in both RCP scenarios. The historical data (from 1963) reveals a decrease in both T_min and T_max; however, validation is unattainable due to data unavailability. All of the months of the year, as well as the overall mean yearly change, demonstrate a positive change point in the future T_min and T_max. The majority of the mean T_min changes in both RCP scenarios are observed between 2033 and 2059 at the end of the near future and the early years of the distant future (Government of Arunachal Pradesh, 2011). A drastic change is likely to be observed for T_min at study point 1 from the year 2052 with as high as 5-10 times in the near future and from 6-15 times in the distant future than the historical in both RCP 4.5 and RCP 8.5, respectively. The other study points for T_min also show an increasing change from 2052 with $14.1 \%$ to $74 \%$ to the historic T_min in both RCPs. Similarly, mean monthly (all 12 months) and annual T_max also show an increasing change point in the scenarios between 2037 and 2074. The mean annual T_max changes for all study points range from $6.6 \%$ to $14.9 \%$ and $8.7 \%$ to $36.4 \%$ to the historic mean T_max in RCP 4.5 and RCP 8.5, respectively.

\section{Conclusions}

Precipitation and temperature are two important variables in the weather system that define a region's climate and varies according to the geographical features and time scale. This paper aims to investigate and quantify the trend and homogeneity in total precipitation, T min, and T max for the RCP 4.5 and RCP 8.5 from 1950 - 2099 using a class of approximately 30-year duration. The study carries three study points across the Tawang Chu in the district of Tawang, Arunachal Pradesh. The NEX-GDDP data is used to complete the study validated using a minimum set of meteorological acquired from the CWC. The historic precipitation trend analysis in the study reveals that there is no significant increasing trend in the annual and seasonal mean precipitation. The summer mean precipitation for RCP 4.5 (2006-2065) shows a positive trend with a positive rise in precipitation between $1.56 \mathrm{~mm}$ to $9.94 \mathrm{~mm}$ in all the study points, which is not observed in the RCP 8.5. The monthly mean precipitation at all study points, there is a clear increasing trend within 12 months for the various time scales- RCP 4.5 April (2036-2065) and October (2066-2095) and a clear downward trend in August (2006-2035), June, and November (2066-2095). The mean annual precipitation statistics show an increase of $10.2 \%$ and $10.7 \%$ than the historic precipitation for RCP 4.5 in 2006-2052 and 2053-2099 at study point 1, which declined for RCP 8.5 than the historical mean annual. Study points 2 and 3 show an increase in mean annual precipitation by $7.5 \%$ to $12.2 \%$ for RCP 4.5 and by $1.4 \%$ to $19.6 \%$ for RCP 8.5 as compared to the historic mean annual. Although decreasing in mean annual precipitation in study point 1 is not in agreement with previous reports and studies (Government of Arunachal Pradesh, 2011; Shivam et al., 2018b), but the increasing total precipitation in the later years of both RCPs in study point 2 and 3 looks in agreement with the report. The mean annual T_min statistics in the study reveal a significant increase against the normal increase of T_max in RCP 4.5, similar to the precipitation statistics and behavior of study point 1 . Both RCP scenarios show a uniform increase in T_min and T_max for study points 2 and 3. The results also show a consistent increase in mean annual T_min and T_max for the three study points. Still, the inter-decadal temperature statistical analysis shows that the increase in mean annual T_min is greater than the increase in T_max, indicating a decreasing trend in DTR (Government of Arunachal Pradesh, 2011; Shivam et al., 2017b). Only a few studies have been conducted in the eastern Himalayan region, particularly in India's Arunachal Pradesh. The lack of similar studies in the Tawang region has resulted in a low comparison between study results and published data. The three study points fall in the Tawang river basin with a large area covered with snow and glacier, which plays an important role in the Tawang basin's hydrology and downstream 
hydrology. Any change in temperature and precipitation can influence the region's hydrology as glacier basins are more sensitive to temperature and precipitation changes. Thus, detailed temperature and precipitation studies can help understand and assess the changes in the basin hydrology and help related affairs (irrigation activities, agricultural, tourism sector, etc.) mitigate with changes.

\section{Declarations:}

\section{-Conflict of Interest}

The authors declare that they have no conflict of interest.

\section{-Funding Statement}

The first author received institute financial support as fellowship provided by Ministry of Education, Govt. of India.

\section{-Author's Contribution}

Juna Probha Devi: Summarized the overall process involved in carrying out the study, data curation, methodology, performed the calculation, compiled the figured and wrote the manuscript.

Chandan Mahanta: Conceptualization, methodology, validation, supervision, writing - review \& editing.

Anamika Barua: Conceptualization, methodology, validation, supervision, writing - review \& editing.

\section{-Availability of data and material}

The data that support the findings of this study are available from the Central Water Commission Shillong and Itanagar, India but restrictions apply to the availability of these data, which were used under licence for the current study, and so are not publicly available. Data are however available from the authors upon reasonable request and with permission of the Central Water Commission Shillong and Itanagar, India.

\section{-Code availability}

There is no code used in this study. All the statistical formulas used in this study are available.

\section{-Ethics approval}

Not applicable

\section{-Consent to participate}

Not applicable

\section{-Consent for publication}

Not applicable

\section{-Corresponding author}

Juna Probha Devi (junapdevi@gmail.com) 


\section{References}

Bapuji Rao, B., Santhibhushan Chowdary, P., Sandeep, V.M., Rao, V.U.M., Venkateswarlu, B., 2014. Rising minimum temperature trends over India in recent decades: Implications for agricultural production. Glob. Planet. Change 117, 1-8. https://doi.org/10.1016/j.gloplacha.2014.03.001

Bhave, A.G., Mittal, N., Mishra, A., Raghuwanshi, N.S., 2016. Integrated Assessment of no-Regret Climate Change Adaptation Options for Reservoir Catchment and Command Areas. Water Resour. Manag. 30, 1001-1018. https://doi.org/10.1007/s11269-015-1207-4

Chakraborty, D., Saha, S., Singh, R.K., Sethy, B.K., Kumar, A., Saikia, U.S., Das, S.K., Makdoh, B., Borah, T.R., Nomita Chanu, A., Walling, I., Rolling Anal, P.S., Chowdhury, S., Daschaudhuri, D., 2017. Trend Analysis and Change Point Detection of Mean Air Temperature: A Spatio-Temporal Perspective of North-Eastern India. Environ. Process. 4, 937-957. https://doi.org/10.1007/s40710-017-0263-6

Dash, S.K., Saraswat, V., Panda, S.K., Sharma, N., 2013. A study of changes in rainfall and temperature patterns at four cities and corresponding meteorological subdivisions over coastal regions of India. Glob. Planet. Change 108, 175-194. https://doi.org/10.1016/j.gloplacha.2013.06.004

Duhan, D., Pandey, A., 2013. Statistical analysis of long term spatial and temporal trends of precipitation during 1901-2002 at Madhya Pradesh, India. Atmos. Res. 122, 136-149. https://doi.org/10.1016/j.atmosres.2012.10.010

Government of Arunachal Pradesh, 2011. Arunachal Pradesh State Action Plan on Climate Change 1-128.

Gurung, D.R., Kulkarni, A. V., Giriraj, A., Aung, K.S., Shrestha, B., Srinivasan, J., 2011. Changes in seasonal snow cover in Hindu Kush-Himalayan region. Cryosph. Discuss. 5, 755-777. https://doi.org/10.5194/tcd$5-755-2011$

Ilori, O.W., Ajayi, V.O., 2020. Change Detection and Trend Analysis of Future Temperature and Rainfall over West Africa. Earth Syst. Environ. 4, 493-512. https://doi.org/10.1007/s41748-020-00174-6

IPCC, 2014. Climate Change 2014: Synthesis Report. Contribution of Working Groups I, II and III to the Fifth Assessment Report of the Intergovernmental Panel on Climate Change, Core Writing Team, R.K. Pachauri and L.A. Meyer. https://doi.org/10.1017/CBO9781107415324.004

Jain, S.K., Kumar, V., Saharia, M., 2013. Analysis of rainfall and temperature trends in northeast India. Int. J. Climatol. 33, 968-978. https://doi.org/10.1002/joc.3483

Kanda, N., Negi, H.S., Rishi, M.S., Kumar, A., 2020. Performance of various gridded temperature and precipitation datasets over Northwest Himalayan Region. Environ. Res. Commun. 2, 085002. https://doi.org/10.1088/2515-7620/ab9991

Kocsis, T., Kovács-Székely, I., Anda, A., 2020. Homogeneity tests and non-parametric analyses of tendencies in precipitation time series in Keszthely, Western Hungary. Theor. Appl. Climatol. 139, 849-859. https://doi.org/10.1007/s00704-019-03014-4

Kolios, A., Mytilinou, V., Lozano-Minguez, E., Salonitis, K., 2016. A Comparative Study of Multiple-Criteria Decision-Making Methods under Stochastic Inputs. Energies 9, 566. https://doi.org/10.3390/en9070566

Kothawale, D.R., Revadekar, J. V., Kumar, K.R., 2010. Recent trends in pre-monsoon daily temperature extremes over India. J. Earth Syst. Sci. 119, 51-65. https://doi.org/10.1007/s12040-010-0008-7

Kousari, M.R., Ahani, H., Hendi-zadeh, R., 2013. Temporal and spatial trend detection of maximum air temperature in Iran during 1960-2005. Glob. Planet. Change 111, 97-110. https://doi.org/10.1016/j.gloplacha.2013.08.011

Kumar, V., Jain, S.K., Singh, Y., 2010. Analysis of long-term rainfall trends in India. Hydrol. Sci. J. 55, 484-496. https://doi.org/10.1080/02626667.2010.481373

Li, H., Haugen, J.E., Xu, C.Y., 2018. Precipitation pattern in the Western Himalayas revealed by four datasets. Hydrol. Earth Syst. Sci. 22, 5097-5110. https://doi.org/10.5194/hess-22-5097-2018

Liu, L., Xu, Z.X., Huang, J.X., 2012. Spatio-temporal variation and abrupt changes for major climate variables in the Taihu Basin, China. Stoch. Environ. Res. Risk Assess. 26, 777-791. https://doi.org/10.1007/s00477011-0547-8 
Liu, Z., Liu, Y., Wang, S., Yang, X., Wang, L., Baig, M.H.A., Chi, W., Wang, Z., 2018. Evaluation of spatial and temporal performances of ERA-interim precipitation and temperature in Mainland China. J. Clim. 31, 43474365. https://doi.org/10.1175/JCLI-D-17-0212.1

Mahjabin, T., Abdul-Aziz, O.I., 2020. Trends in the magnitude and frequency of extreme rainfall regimes in Florida. Water (Switzerland) 12. https://doi.org/10.3390/W12092582

Malik, S., Pal, S.C., Sattar, A., Singh, S.K., Das, B., Chakrabortty, R., Mohammad, P., 2020. Trend of extreme rainfall events using suitable Global Circulation Model to combat the water logging condition in Kolkata Metropolitan Area. Urban Clim. 32, 100599. https://doi.org/10.1016/j.uclim.2020.100599

Milentijević, N., Bačević, N., Ristić, D., Valjarević, A., Pantelić, M., Kićović, D., 2020. Application of MannKendal (MK) test in trend analysis of air temperature and precipitation: Case of Mačva district (Serbia). Univ. Thought - Publ. Nat. Sci. 10, 37-43. https://doi.org/10.5937/univtho10-24774

Mir, R.A., Jain, S.K., Saraf, A., Goswami, A., 2015. Accuracy assessment and trend analysis of MODIS-derived data on snow- International Journal of Remote Accuracy assessment and trend analysis of MODIS-derived data on snow-covered areas in the Sutlej basin , Western Himalayas. https://doi.org/10.1080/01431161.2015.1070320

Mulliner, E., Malys, N., Maliene, V., 2016. Comparative analysis of MCDM methods for the assessment of sustainable housing affordability. Omega (United Kingdom) 59, 146-156. https://doi.org/10.1016/j.omega.2015.05.013

Pettitt, A.N., 1979. A Non-Parametric Approach to the Change-Point Problem. Appl. Stat. $28,126$. https://doi.org/10.2307/2346729

Radinović, D., Curić, M., 2014. Measuring scales for daily temperature extremes, precipitation and wind velocity. Meteorol. Appl. 21, 461-465. https://doi.org/10.1002/met.1356

Scherler, D., Bookhagen, B., Strecker, M.R., 2011. Spatially variable response of Himalayan glaciers to climate change affected by debris cover. Nat. Geosci. 4, 156-159. https://doi.org/10.1038/ngeo1068

Sharma, A., Goyal, M.K., 2020. Assessment of the changes in precipitation and temperature in Teesta River basin in Indian Himalayan Region under climate change. Atmos. Res. 231, 104670. https://doi.org/10.1016/j.atmosres.2019.104670

Sharma, C.S., Behera, M.D., Mishra, A., Panda, S.N., 2011. Assessing Flood Induced Land-Cover Changes Using Remote Sensing and Fuzzy Approach in Eastern Gujarat (India). Water Resour. Manag. 25, 3219-3246. https://doi.org/10.1007/s11269-011-9853-7

Sharma, C.S., Panda, S.N., Pradhan, R.P., Singh, A., Kawamura, A., 2016. Precipitation and temperature changes in eastern India by multiple trend detection methods. Atmos. Res. 180, 211-225. https://doi.org/10.1016/j.atmosres.2016.04.019

Shifteh Some'e, B., Ezani, A., Tabari, H., 2012. Spatiotemporal trends and change point of precipitation in Iran. Atmos. Res. 113, 1-12. https://doi.org/10.1016/j.atmosres.2012.04.016

Shivam, G., Goyal, M.K., Sarma, A.K., 2018a. Index-Based Study of Future Precipitation Changes over Subansiri River Catchment under Changing Climate. J. Environ. Informatics. https://doi.org/10.3808/jei.201700376

Shivam, G., Goyal, M.K., Sarma, A.K., 2018b. Index-Based Study of Future Precipitation Changes over Subansiri River Catchment under Changing Climate. J. Environ. Informatics 34, 1-14. https://doi.org/10.3808/jei.201700376

Shivam, Goyal, M.K., Sarma, A.K., 2017a. Analysis of the change in temperature trends in Subansiri River basin for RCP scenarios using CMIP5 datasets. Theor. Appl. Climatol. 129, 1175-1187. https://doi.org/10.1007/s00704-016-1842-6

Shivam, Goyal, M.K., Sarma, A.K., 2017b. Analysis of the change in temperature trends in Subansiri River basin for RCP scenarios using CMIP5 datasets. Theor. Appl. Climatol. 129, 1175-1187. https://doi.org/10.1007/s00704-016-1842-6

Tang, S., Li, R., He, J., Wang, H., Fan, X., Yao, S., 2020. Comparative Evaluation of the GPM IMERG Early, Late, and Final Hourly Precipitation Products Using the CMPA Data over Sichuan Basin of China. Water 
12, 554. https://doi.org/10.3390/w12020554

Triantaphyllou, E., 2000. Multi-Criteria Decision Making Methods, in: Springer, Boston, MA. pp. 5-21. https://doi.org/10.1007/978-1-4757-3157-6_2

Yürekli, K., 2015. Impact of climate variability on precipitation in the Upper Euphrates-Tigris Rivers Basin of Southeast Turkey. Atmos. Res. 154, 25-38. https://doi.org/10.1016/j.atmosres.2014.11.002

Zhang, Q., Gu, X., Singh, V.P., Kong, D., Chen, X., 2015. Spatiotemporal behavior of floods and droughts and their impacts on agriculture in China. Glob. Planet. Change 131, 63-72. https://doi.org/10.1016/j.gloplacha.2015.05.007

Zhang, Y., Hanati, G., Danierhan, S., Liu, Q., Xu, Z., 2020. Evaluation and comparison of daily gpm/trmm precipitation products over the tianshan mountains in china. Water (Switzerland) 12. https://doi.org/10.3390/w12113088 


\section{Figures}

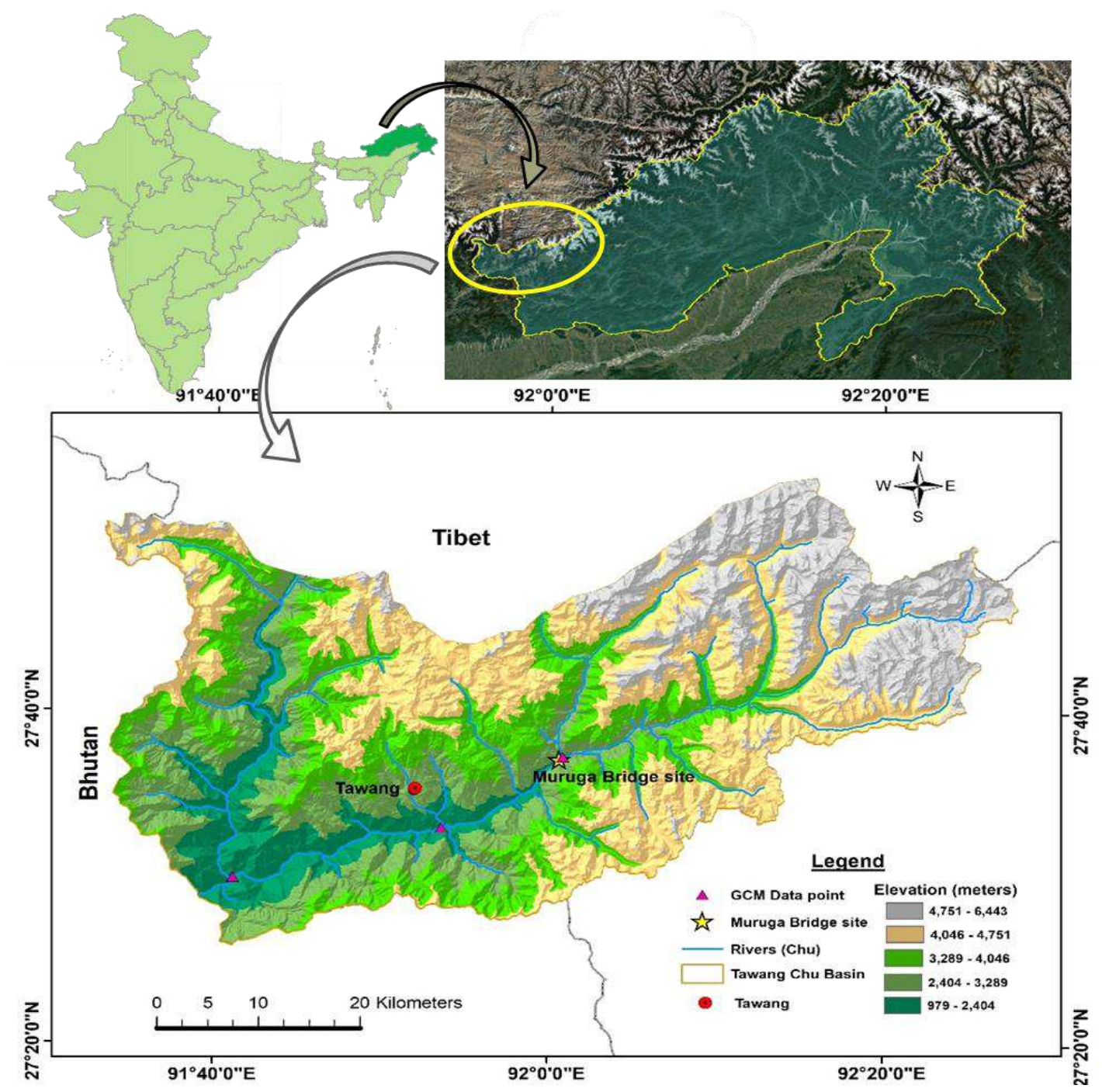

Fig. 1. Location map of the study area. 


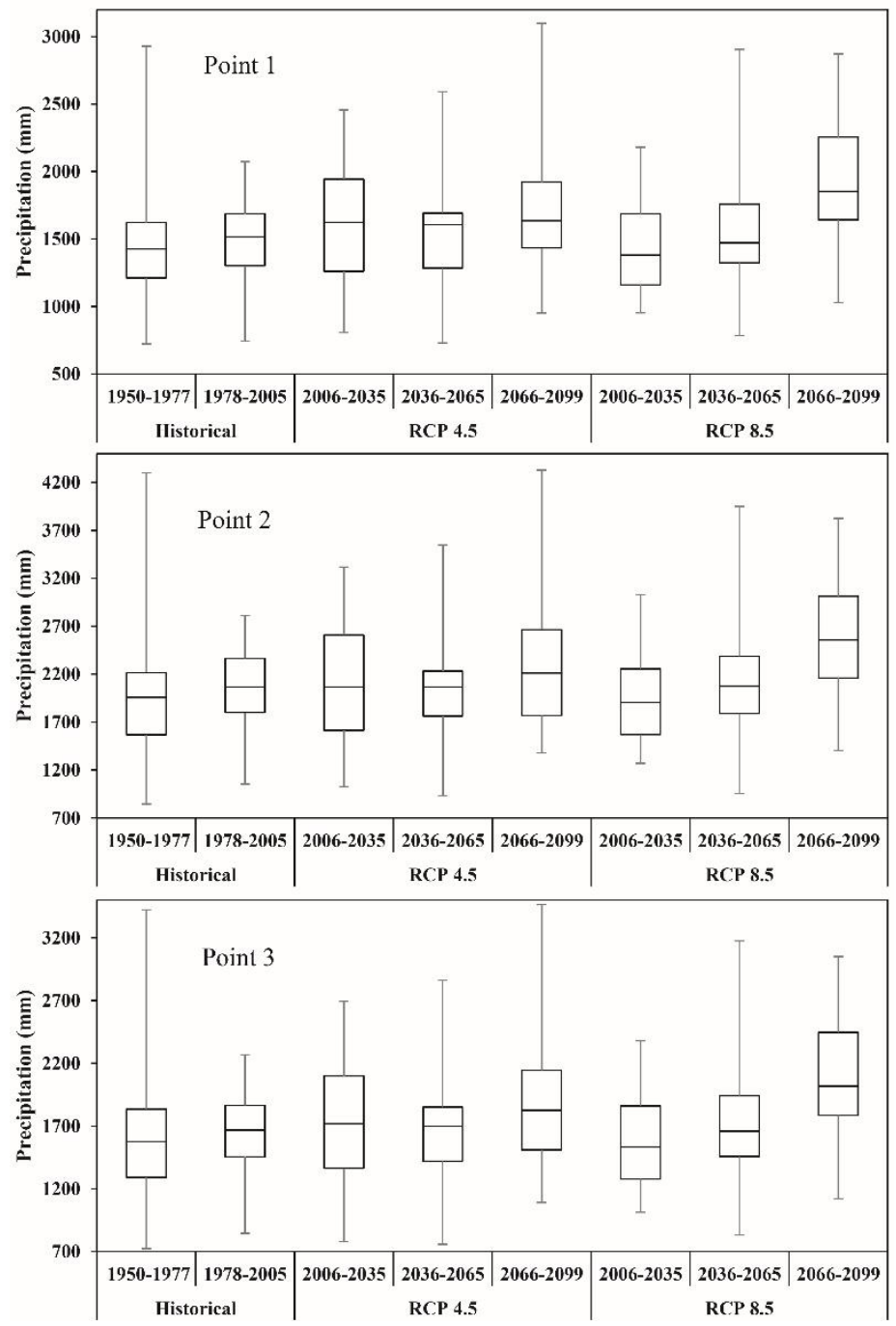

Fig. 2. Box-plot of historical (1950-2005) and futuristic RCP 4.5 and RCP 8.5 scenarios (2006-2099) precipitation for different time scale over all the study points. 
(a)

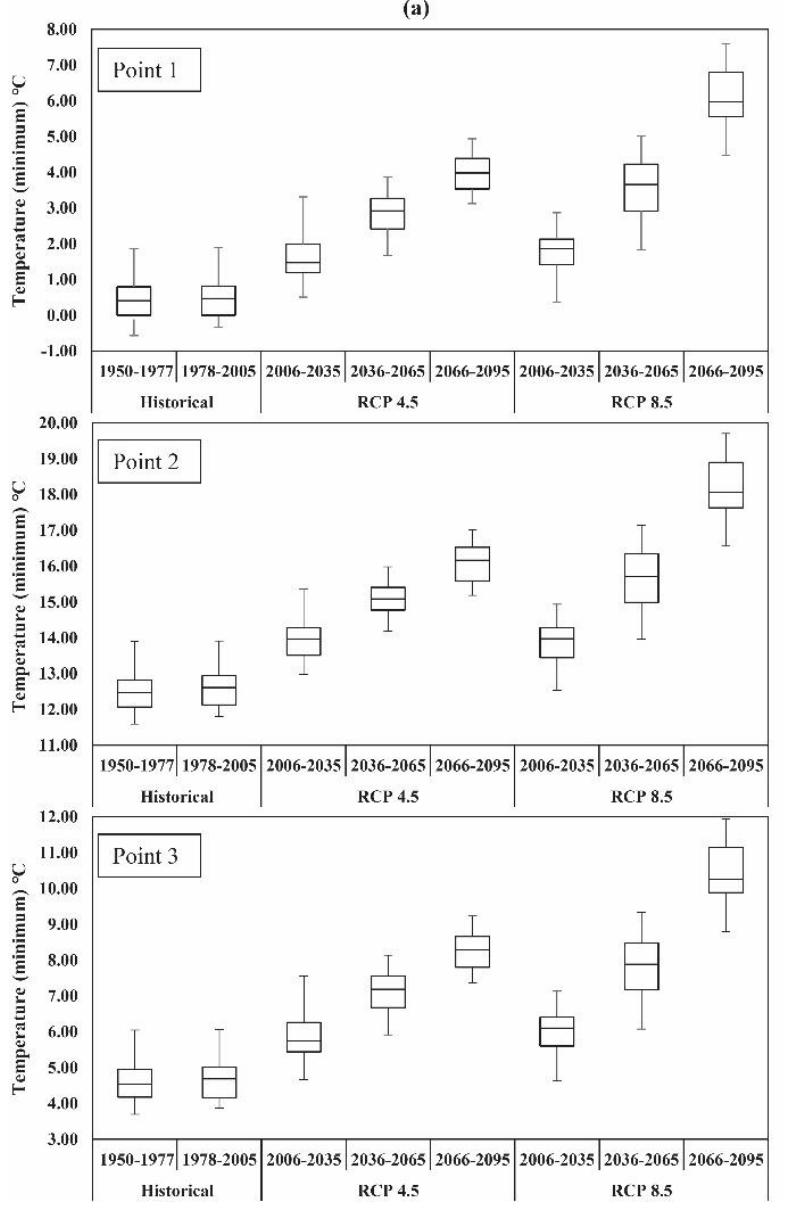

(b)

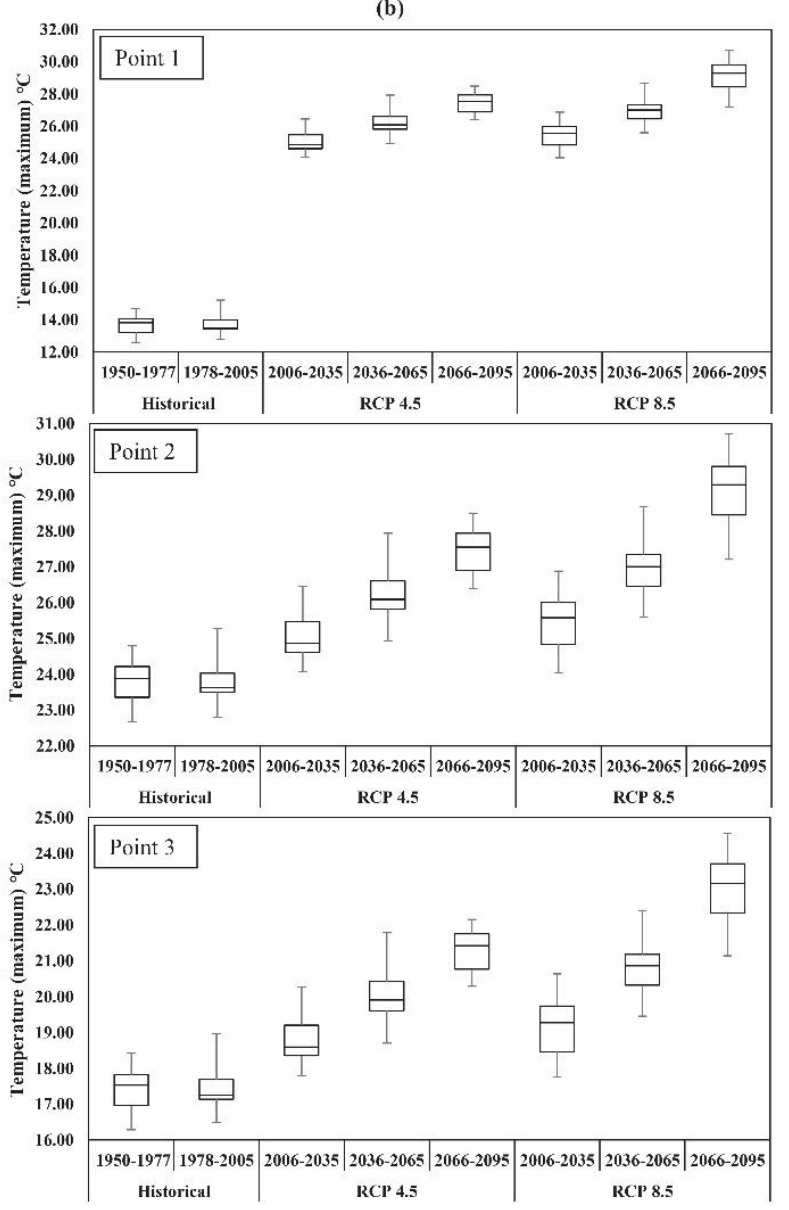

Fig. 3. Box-plot of historical (1950-2005) and futuristic RCP 4.5 and RCP 8.5 scenarios (2006-2099) temperature(a) T_min and (b) T_max for different time scale over all the study points. 

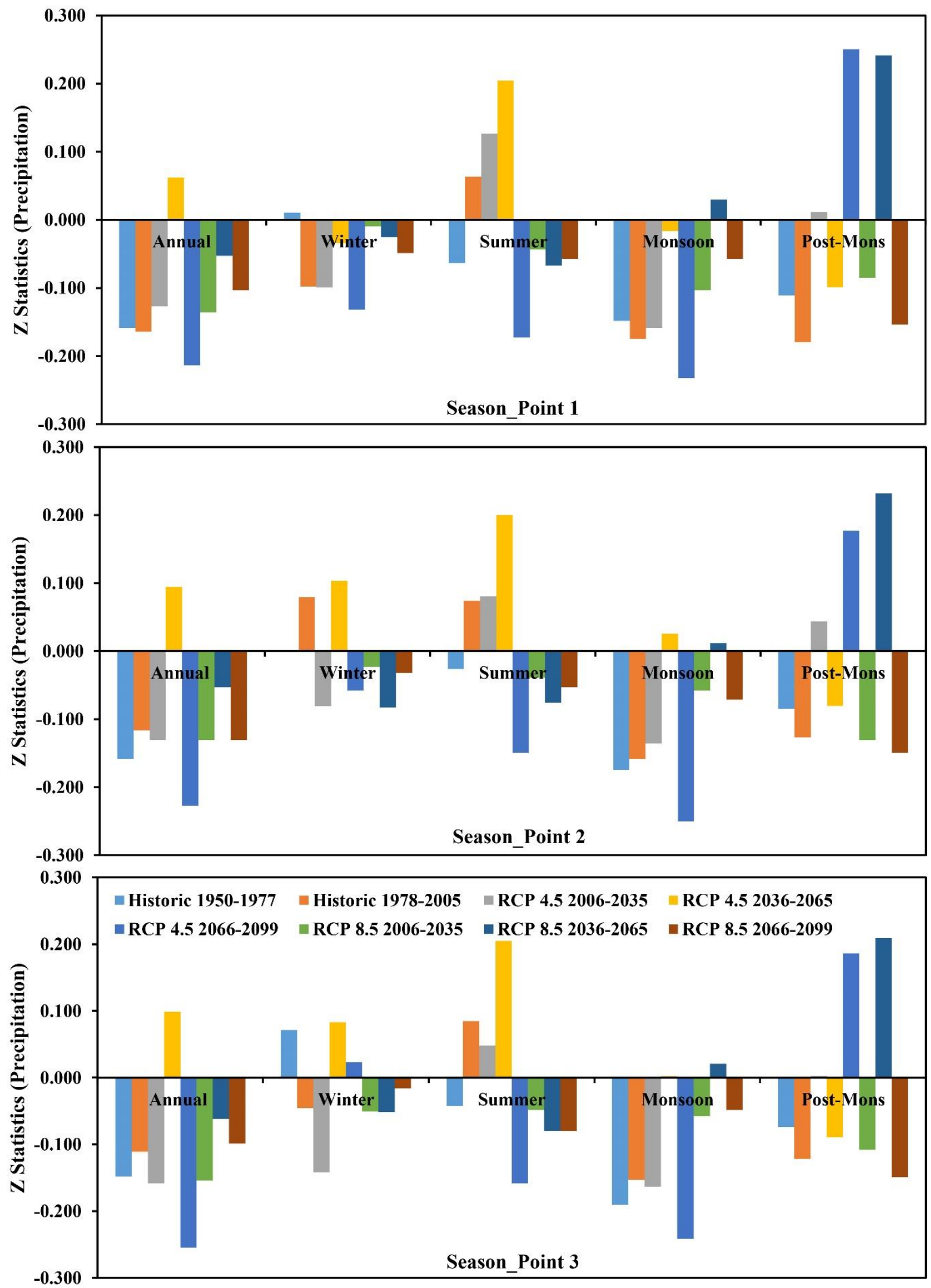

Fig. 4. Mann-Kendall test Z-statistics of annual and seasonal precipitation during historic period (1950-2005) and RCP 4.5 and RCP 8.5 scenarios (2006-2099) over all the study points. 


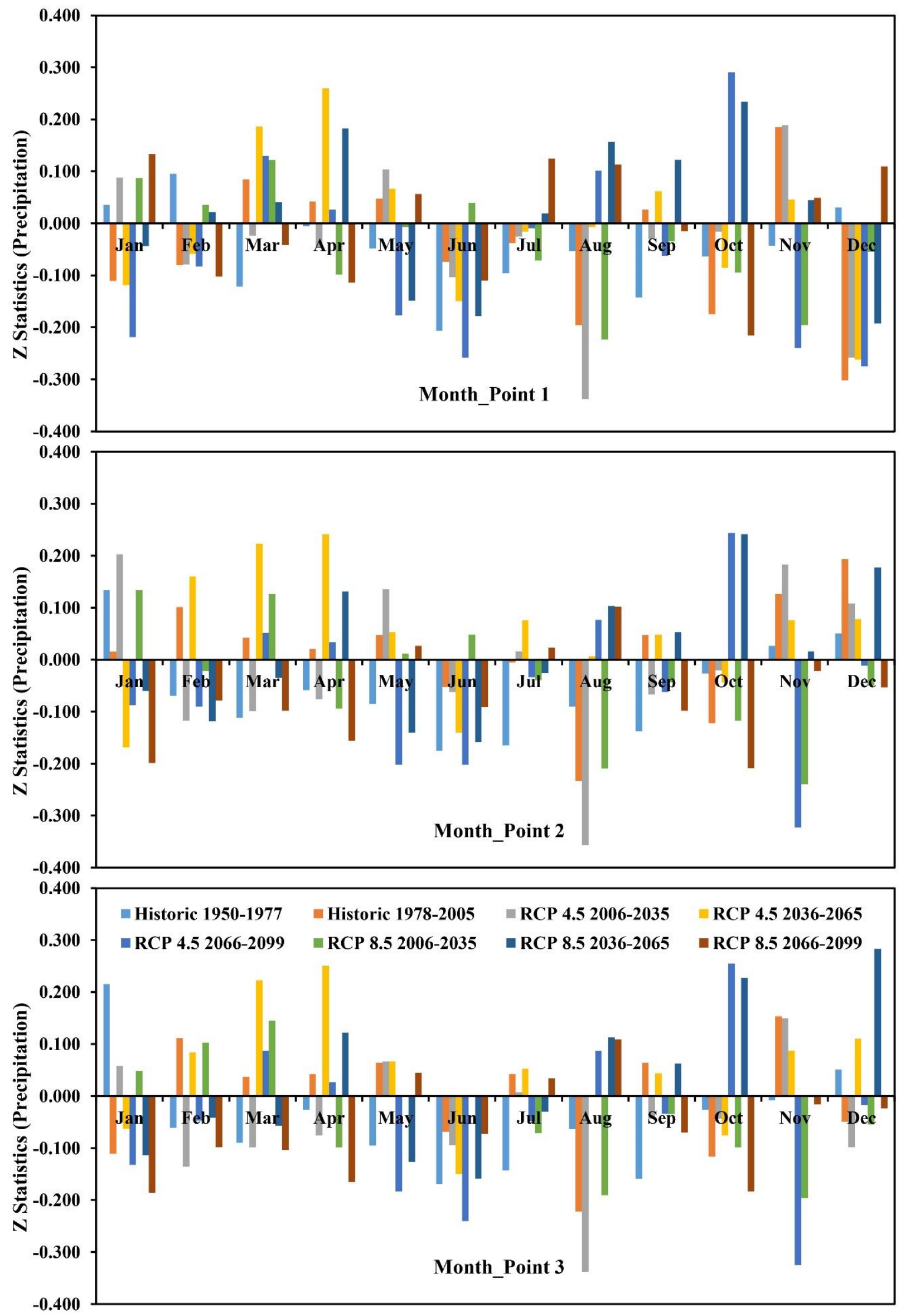

Fig. 5. Mann-Kendall test Z-statistics of monthly precipitation during historical period (1950-2005) and RCP 4.5 and RCP 8.5 scenarios (2006-2099) over all the study points. 
(a)

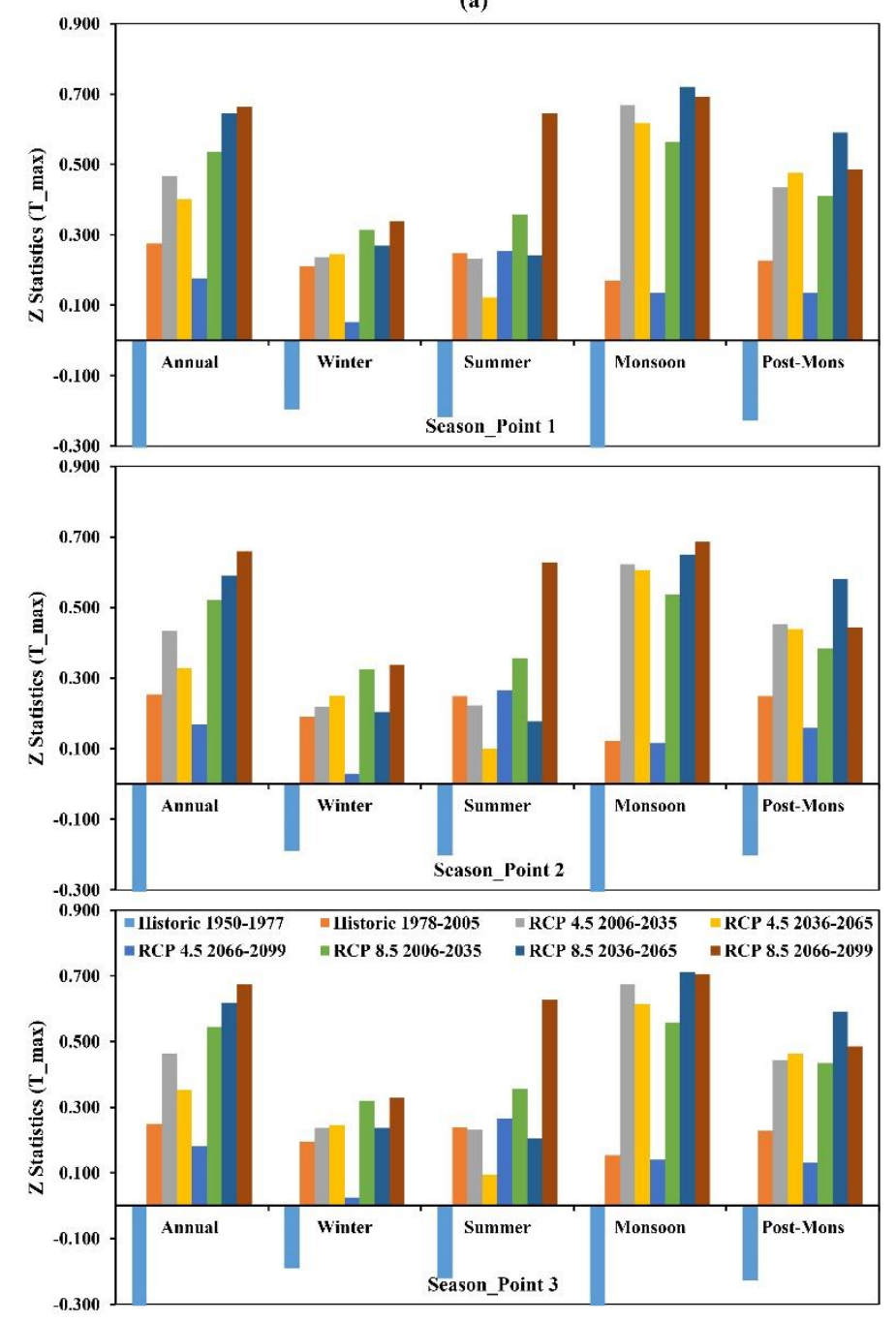

(b)
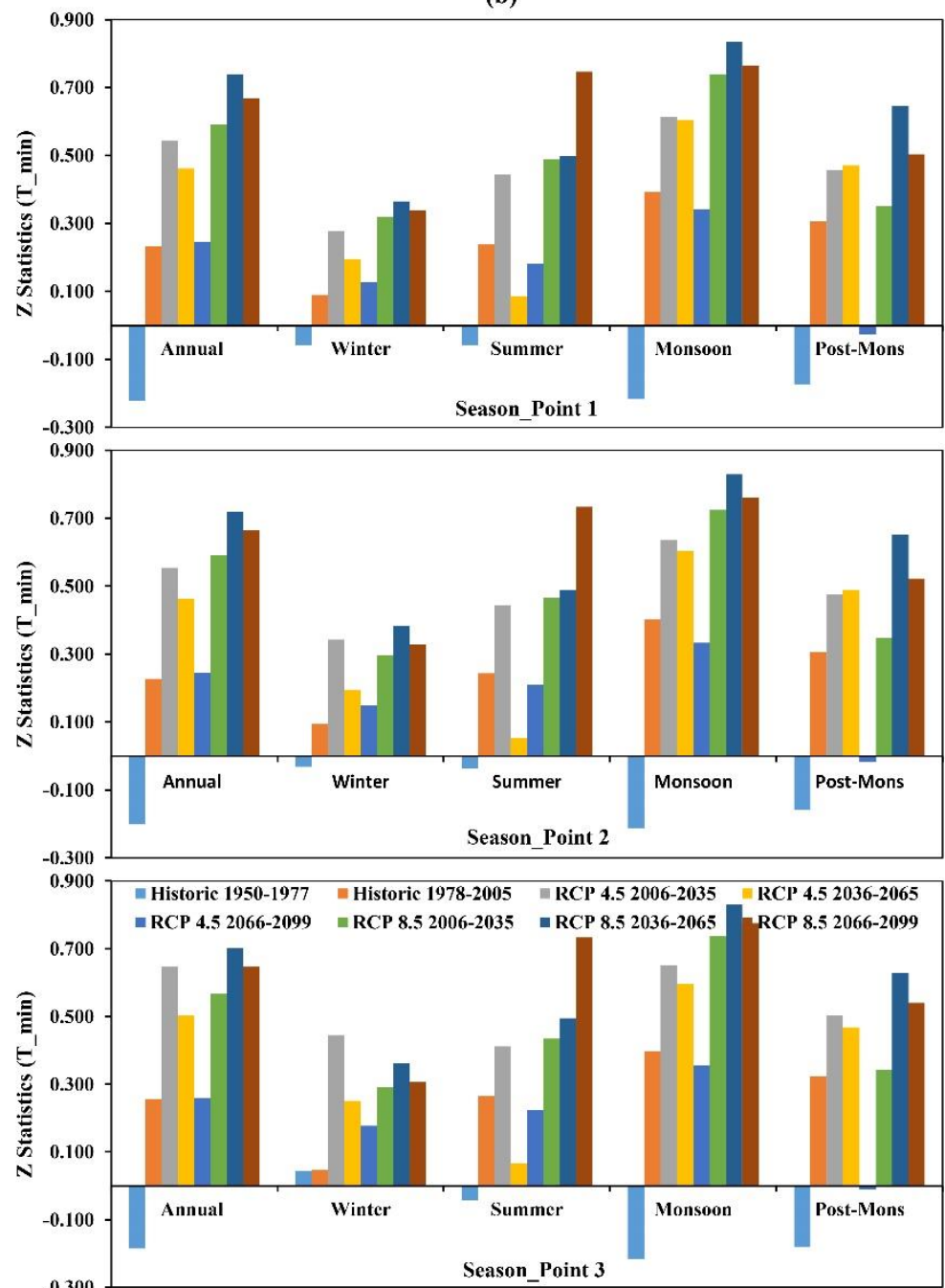

Fig. 6. Mann-Kendall test Z-statistics of (a) T max and (b) T min for annual and seasonal periods over the historical period (1950-2005) and RCP 4.5 and 8.5 scenarios (20062099) over the study points. 
(a)
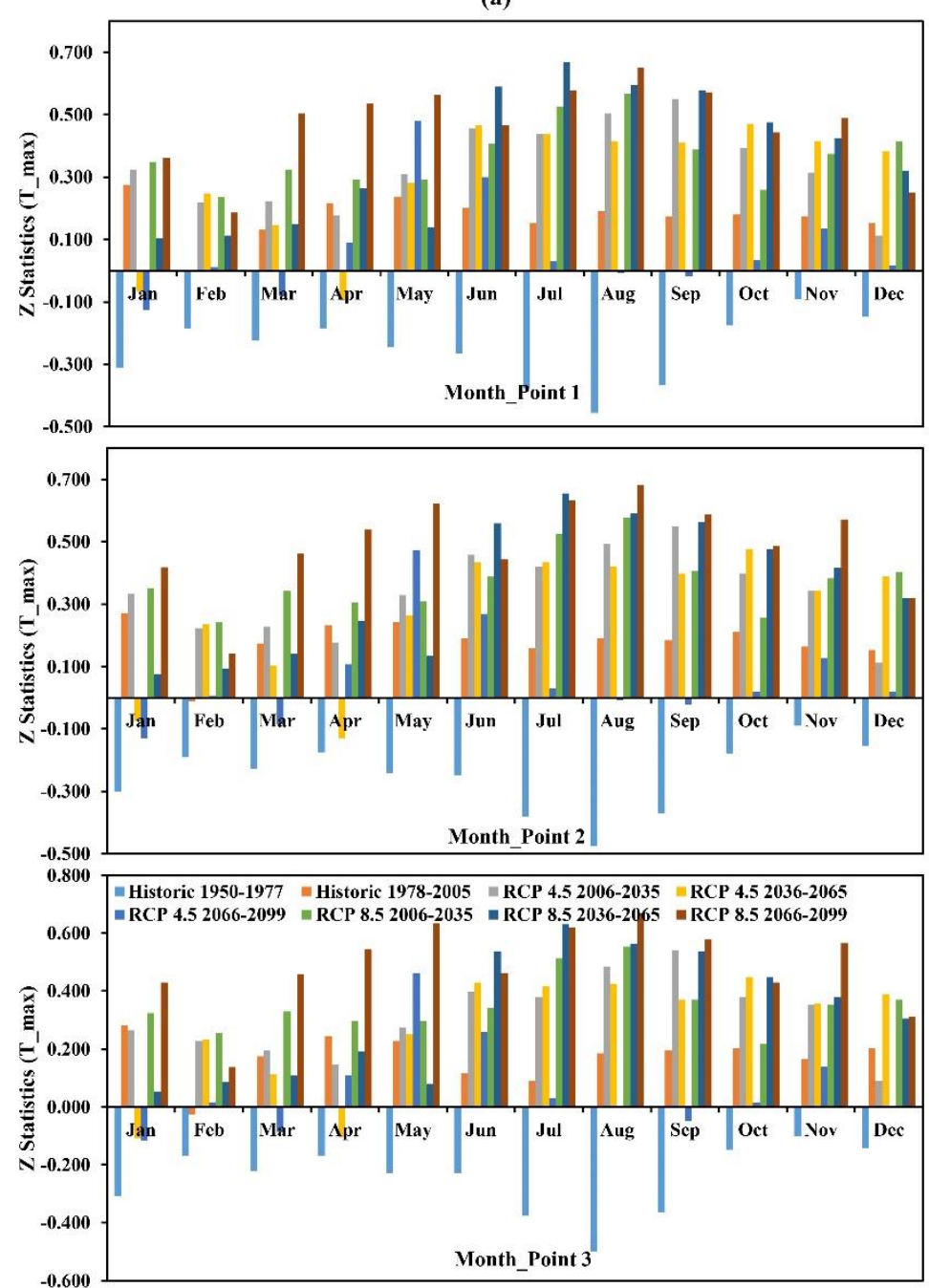

(b)
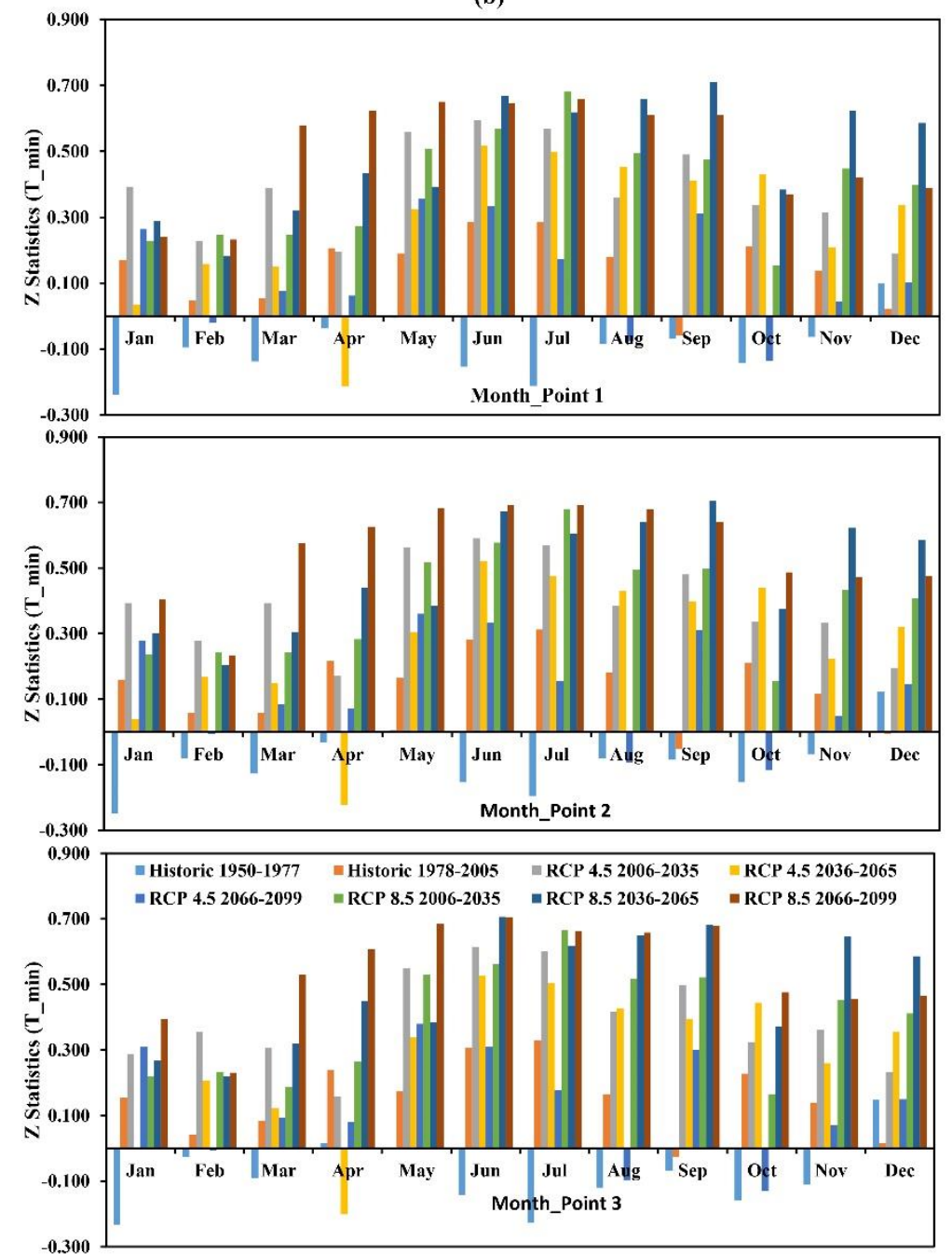

Fig. 7. Mann-Kendall test Z-statistics of monthly (a) T max and (b) T min during the historical era (1950-2005) and RCP 4.5 and 8.5 scenarios (2006-2099) over all the study points. 


\section{Tables}

Table 1. Location of study points with geographical extension and elevation.

\begin{tabular}{cccc}
\hline Location point & Latitude & Longitude & Altitude (m) \\
\hline Point 1 & $27^{\circ} 37^{\prime} 04^{\prime \prime}$ & $92^{\circ} 00^{\prime} 28^{\prime \prime}$ & 2401 \\
Point 2 & $27^{\circ} 33^{\prime} 03^{\prime \prime}$ & $91^{\circ} 53^{\prime} 34^{\prime \prime}$ & 1733 \\
Point 3 & $27^{\circ} 29^{\prime} 59^{\prime \prime}$ & $91^{\circ} 41^{\prime} 07^{\prime \prime}$ & 1081 \\
\hline
\end{tabular}


Table 2. List of GCMs used for replicating ERA5-Land hourly reanalysis dataset.

\begin{tabular}{|c|c|c|c|}
\hline S. No. & GCM name & Institution & Source \\
\hline 1 & ACCESS1 & $\begin{array}{l}\text { Australian Community Climate and Earth-System Simulator, } \\
\text { version } 1.0\end{array}$ & Australia \\
\hline 2 & BNU-ESM & Beijing Normal University Earth System Model & China \\
\hline 3 & CCSM4 & National Center for Atmospheric Research & United States \\
\hline 4 & CESM1-BGC & $\begin{array}{l}\text { Community Earth System Model, version 1-Biogeochemistry, } \\
\text { National Science Foundation, Department of Energy, \& } \\
\text { National Center for Atmospheric Research }\end{array}$ & United States \\
\hline 5 & CNRM-CM5 & $\begin{array}{l}\text { Centre National de Recherches Meteorologiques/Centre } \\
\text { Europeen de Recherche et Formation Avancees en Calcul } \\
\text { Scientifique }\end{array}$ & France \\
\hline 6 & $\begin{array}{l}\text { CSIRO-Mk3-6- } \\
0\end{array}$ & $\begin{array}{l}\text { Commonwealth Scientific and Industrial Research } \\
\text { Organization in collaboration with Queensland Climate } \\
\text { Change Centre of Excellence }\end{array}$ & Australia \\
\hline 7 & CanESM2 & $\begin{array}{l}\text { Second generation Canadian Earth System Model, Canadian } \\
\text { Centre for Climate Modelling and Analysis (CCCma) of } \\
\text { Environment and Climate Change Canada }\end{array}$ & Canada \\
\hline 8 & GFDL-CM3 & NASA Geophysical Fluid Dynamics Laboratory & United States \\
\hline 9 & GFDL-ESM2G & $\begin{array}{l}\text { Geophysical Fluid Dynamics Laboratory Earth System Model } \\
\text { with Generalized Ocean Layer Dynamics (GOLD) component }\end{array}$ & United States \\
\hline 10 & GFDL-ESM2M & $\begin{array}{l}\text { Geophysical Fluid Dynamics Laboratory Earth System Model } \\
\text { with Modular Ocean Model } 4 \text { (MOM4) component }\end{array}$ & United States \\
\hline 11 & $\begin{array}{l}\text { IPSL-CM5A- } \\
\text { LR }\end{array}$ & L'Institut Pierre-Simon Laplace Coupled Model, version 5A, & France \\
\hline 12 & $\begin{array}{l}\text { IPSL-CM5A- } \\
\text { MR }\end{array}$ & L'Institut Pierre-Simon Laplace Coupled Model, version 5A & France \\
\hline
\end{tabular}


Table 3. List of the statistical method.

\begin{tabular}{ccc}
\hline Statistical Method & Equation & Optimal Value \\
\hline Bias (\%) & $\sum_{i=1}^{n} \frac{o b s_{i}-E s t_{i}}{\sum_{i=1}^{n} O b s_{i}} * 100$ & 0 \\
Pearson's Correlation coefficient & $\frac{\sum_{i=1}^{n}\left(O b s_{i}-\overline{O b s}\right)\left(E s t_{i}-\overline{E s t}\right)}{\sqrt{\sum_{i=1}^{n}\left(O b s_{i}-\overline{O b s}\right)^{2}} \sqrt{\sum_{i=1}^{n}\left(E s t_{i}-\overline{E s t}\right)^{2}}}$ & 1 \\
Root Mean Square Error (RMSE) & $\sqrt{\frac{\sum_{i=1}^{n}\left|O b s_{i}-E s t_{i}\right|^{2}}{n}}$ & 0 \\
Mean Absolute Error (MAE) & $\frac{\sum_{i=1}^{n}\left|O b s_{i}-E s t_{i}\right|}{n}$ \\
\hline
\end{tabular}

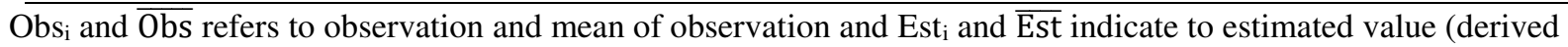
from NEXGDDP data) and mean of estimated value, respectively. 
Table 4. Mann-Kendall test Z-statistics and Sen's slope (mm/year) for the study points with mean annual and seasonal precipitation for historical (1950-2005) and futuristic (2006-2095) for RCP 4.5 and RCP 8.5 scenarios.

\begin{tabular}{|c|c|c|c|c|c|c|c|c|c|c|c|c|}
\hline \multirow{2}{*}{ Station } & \multirow{2}{*}{\multicolumn{2}{|c|}{ Time Scale/Seasons }} & \multicolumn{2}{|c|}{ Annual } & \multicolumn{2}{|c|}{ Winter } & \multicolumn{2}{|c|}{ Summer } & \multicolumn{2}{|c|}{ Monsoon } & \multicolumn{2}{|c|}{ Post-Monsoon } \\
\hline & & & $\mathbf{Z}$ & Slope & $\mathbf{Z}$ & Slope & $\mathbf{Z}$ & Slope & $\mathbf{Z}$ & Slope & $\mathbf{Z}$ & Slope \\
\hline \multirow{8}{*}{ SB 1} & \multirow{2}{*}{ Historical } & $1950-1977$ & -0.16 & -12.26 & 0.01 & 0.00 & -0.06 & -1.37 & -0.15 & -6.77 & -0.11 & -1.00 \\
\hline & & $1978-2005$ & -0.16 & -8.94 & -0.10 & -0.01 & 0.06 & 2.70 & -0.17 & -7.96 & -0.18 & -1.10 \\
\hline & \multirow{3}{*}{ RCP 4.5} & $2006-2035$ & -0.13 & -10.56 & -0.10 & -0.01 & 0.13 & 2.75 & -0.16 & -11.55 & 0.01 & 0.07 \\
\hline & & $2036-2065$ & 0.06 & 3.48 & -0.03 & 0.00 & 0.20 & 5.94 & -0.02 & -1.68 & -0.10 & -0.85 \\
\hline & & $2066-2095$ & -0.21 & -18.58 & -0.13 & -0.01 & -0.17 & -5.79 & -0.23 & -12.15 & 0.25 & 1.96 \\
\hline & \multirow{3}{*}{ RCP 8.5} & $2006-2035$ & -0.14 & -7.98 & -0.01 & 0.00 & -0.04 & -1.46 & -0.10 & -6.41 & -0.09 & -0.83 \\
\hline & & $2036-2065$ & -0.05 & -2.97 & -0.03 & 0.00 & -0.07 & -3.56 & 0.03 & 2.34 & 0.24 & 2.45 \\
\hline & & 2066-2099 & -0.10 & -11.97 & -0.05 & -0.01 & -0.06 & -2.09 & -0.06 & -3.43 & -0.15 & -1.56 \\
\hline \multirow{8}{*}{ SB 2} & \multirow{2}{*}{ Historical } & $1950-1977$ & -0.16 & -18.16 & 0.00 & 0.00 & -0.03 & -1.10 & -0.17 & -10.49 & -0.08 & -0.77 \\
\hline & & $1978-2005$ & -0.12 & -9.84 & 0.08 & 0.08 & 0.07 & 4.00 & -0.16 & -8.21 & -0.13 & -1.06 \\
\hline & \multirow{3}{*}{ RCP 4.5} & $2006-2035$ & -0.13 & -14.38 & -0.08 & -0.06 & 0.08 & 3.51 & -0.14 & -12.38 & 0.04 & 0.68 \\
\hline & & $2036-2065$ & 0.09 & 9.14 & 0.10 & 0.08 & 0.20 & 9.94 & 0.03 & 1.11 & -0.08 & -1.55 \\
\hline & & 2066-2099 & -0.23 & -22.15 & -0.06 & -0.04 & -0.15 & -7.82 & -0.25 & -20.62 & 0.18 & 2.80 \\
\hline & \multirow{3}{*}{ RCP 8.5} & $2006-2035$ & -0.13 & -10.84 & -0.02 & -0.02 & -0.04 & -0.75 & -0.06 & -6.40 & -0.13 & -1.68 \\
\hline & & $2036-2065$ & -0.05 & -5.88 & -0.08 & -0.07 & -0.08 & -6.61 & 0.01 & 0.95 & 0.23 & 3.19 \\
\hline & & 2066-2099 & -0.13 & -20.45 & -0.03 & -0.04 & -0.05 & -4.70 & -0.07 & -9.85 & -0.15 & -2.54 \\
\hline \multirow{8}{*}{ SB 3} & \multirow{2}{*}{ Historical } & $1950-1977$ & -0.15 & -15.25 & 0.07 & 0.03 & -0.04 & -1.46 & -0.19 & -8.62 & -0.07 & -0.69 \\
\hline & & $1978-2005$ & -0.11 & -6.16 & -0.05 & -0.01 & 0.08 & 3.88 & -0.15 & -6.69 & -0.12 & -0.87 \\
\hline & \multirow{3}{*}{ RCP 4.5} & $2006-2035$ & -0.16 & -13.83 & -0.14 & -0.05 & 0.05 & 1.56 & -0.16 & -13.46 & 0.00 & 0.02 \\
\hline & & $2036-2065$ & 0.10 & 7.78 & 0.08 & 0.03 & 0.20 & 7.26 & 0.00 & 0.63 & -0.09 & -1.15 \\
\hline & & 2066-2099 & -0.26 & -21.57 & 0.02 & 0.00 & -0.16 & -7.24 & -0.24 & -17.29 & 0.19 & 1.83 \\
\hline & \multirow{3}{*}{ RCP 8.5} & $2006-2035$ & -0.15 & -8.74 & -0.05 & -0.01 & -0.05 & -1.10 & -0.06 & -3.63 & -0.11 & -1.03 \\
\hline & & $2036-2065$ & -0.06 & -4.46 & -0.05 & -0.01 & -0.08 & -4.08 & 0.02 & 0.70 & 0.21 & 2.65 \\
\hline & & 2066-2099 & -0.10 & -12.47 & -0.02 & 0.00 & -0.08 & -3.68 & -0.05 & -4.95 & -0.15 & -1.50 \\
\hline
\end{tabular}

Bold numbers show a significant trend at a $95 \%$ confidence level. 
Table 5. Mann-Kendall test Z-statistics and Sen's slope (mm/year) for the study points (sub-basin level) of mean monthly precipitation for historical (1950-2005) and futuristic (2006-2095) with RCP 4.5 and RCP 8.5 scenarios.

\begin{tabular}{|c|c|c|c|c|c|c|c|c|c|c|c|c|c|c|c|c|c|c|c|c|c|c|c|c|c|c|}
\hline \multirow{2}{*}{ Station } & \multirow{2}{*}{\multicolumn{2}{|c|}{$\begin{array}{c}\text { Time } \\
\text { Scale/Months } \\
\end{array}$}} & \multirow{2}{*}{\multicolumn{2}{|c|}{$\begin{array}{l}\text { Jan } \\
7 \quad \text { Slone }\end{array}$}} & \multicolumn{2}{|c|}{ Feb } & \multicolumn{2}{|c|}{ Mar } & \multicolumn{2}{|c|}{ Apr } & \multicolumn{2}{|c|}{ May } & \multicolumn{2}{|c|}{ Jun } & \multicolumn{2}{|c|}{ Jul } & \multicolumn{2}{|c|}{ Aug } & \multicolumn{2}{|c|}{ Sep } & \multicolumn{2}{|c|}{ Oct } & \multicolumn{2}{|c|}{ Nov } & \multicolumn{2}{|c|}{ Dec } \\
\hline & & & & Slope & $\mathbf{Z}$ & Slope & $\mathbf{Z}$ & Slope & $\mathbf{Z}$ & Slope & $\mathbf{Z}$ & Slope & $\mathbf{Z}$ & Slope & $\mathbf{Z}$ & Slope & $\mathbf{Z}$ & Slope & $\mathbf{Z}$ & Slope & $\mathbf{Z}$ & Slope & $\mathbf{Z}$ & Slope & $\mathbf{Z}$ & Slope \\
\hline \multirow{8}{*}{ SB 1} & \multirow{2}{*}{ Historical } & $\begin{array}{c}1950- \\
1977\end{array}$ & 0.04 & 0.00 & 0.10 & 0.00 & -0.12 & -0.22 & -0.01 & -0.03 & -0.05 & -0.35 & -0.21 & -6.32 & -0.10 & -3.00 & -0.05 & -1.08 & -0.14 & -2.38 & -0.06 & -0.49 & -0.04 & -0.03 & 0.03 & 0.00 \\
\hline & & $\begin{array}{l}1978- \\
2005 \\
\end{array}$ & -0.11 & 0.00 & -0.08 & 0.00 & 0.08 & 0.16 & 0.04 & 0.25 & 0.05 & 0.78 & -0.07 & -2.42 & -0.04 & -0.68 & -0.20 & -5.38 & 0.03 & 0.68 & -0.17 & -1.25 & 0.19 & 0.09 & -0.30 & 0.00 \\
\hline & \multirow{3}{*}{ RCP 4.5} & $\begin{array}{l}2006- \\
2035\end{array}$ & 0.09 & 0.00 & -0.08 & 0.00 & -0.02 & -0.06 & -0.04 & -0.46 & 0.10 & 1.59 & -0.10 & -2.29 & -0.03 & -0.43 & -0.34 & -7.90 & -0.03 & -0.69 & -0.02 & -0.22 & 0.19 & 0.11 & -0.26 & 0.00 \\
\hline & & $\begin{array}{l}2036- \\
2065\end{array}$ & -0.12 & 0.00 & -0.06 & 0.00 & 0.19 & 0.48 & 0.26 & 3.40 & 0.07 & 1.06 & -0.15 & -5.15 & -0.02 & -0.29 & -0.01 & -0.10 & 0.06 & 1.16 & -0.09 & -0.96 & 0.05 & 0.02 & -0.26 & 0.00 \\
\hline & & $\begin{array}{l}2066- \\
2095 \\
\end{array}$ & -0.22 & 0.00 & -0.08 & 0.00 & 0.13 & 0.32 & 0.03 & 0.52 & -0.18 & -2.90 & -0.26 & -6.91 & -0.01 & -0.19 & 0.10 & 2.95 & -0.06 & -1.15 & 0.29 & 2.17 & -0.24 & -0.20 & -0.27 & 0.00 \\
\hline & \multirow{3}{*}{ RCP 8.5} & $\begin{array}{l}2006- \\
2035\end{array}$ & 0.09 & 0.00 & 0.04 & 0.00 & 0.12 & 0.31 & -0.10 & -1.01 & -0.01 & -0.33 & 0.04 & 0.66 & -0.07 & -1.20 & -0.22 & -5.31 & -0.03 & -0.87 & -0.09 & -0.54 & -0.20 & -0.12 & -0.05 & 0.00 \\
\hline & & $\begin{array}{l}2036- \\
2065\end{array}$ & -0.04 & 0.00 & 0.02 & 0.00 & 0.04 & 0.14 & 0.18 & 2.97 & -0.15 & -2.95 & -0.18 & -4.49 & 0.02 & 0.16 & 0.16 & 1.99 & 0.12 & 2.65 & 0.23 & 1.92 & 0.05 & 0.02 & -0.19 & 0.00 \\
\hline & & $\begin{array}{c}2066- \\
2095 \\
\end{array}$ & 0.13 & 0.00 & -0.10 & -0.01 & -0.04 & -0.21 & -0.11 & -2.04 & 0.06 & 1.23 & -0.11 & -3.29 & 0.13 & 3.27 & 0.11 & 2.97 & -0.02 & -0.24 & -0.22 & -2.29 & 0.05 & 0.02 & 0.11 & 0.00 \\
\hline \multirow{8}{*}{ SB 2} & \multirow{2}{*}{ Historical } & $\begin{array}{l}1950- \\
1977\end{array}$ & 0.13 & 0.04 & -0.07 & -0.03 & -0.11 & -0.30 & -0.06 & -0.37 & -0.08 & -1.27 & -0.17 & -5.61 & -0.16 & -6.59 & -0.09 & -2.16 & -0.14 & -2.82 & -0.03 & -0.25 & 0.03 & 0.03 & 0.05 & 0.00 \\
\hline & & $\begin{array}{l}1978- \\
2005\end{array}$ & 0.02 & 0.01 & 0.10 & 0.03 & 0.04 & 0.14 & 0.02 & 0.48 & 0.05 & 0.89 & -0.05 & -2.19 & -0.01 & -0.14 & -0.23 & -7.94 & 0.05 & 1.47 & -0.12 & -1.28 & 0.13 & 0.08 & 0.19 & 0.00 \\
\hline & \multirow{3}{*}{ RCP 4.5} & $2006-$ & 0.20 & 0.02 & -0.12 & -0.02 & -0.10 & -0.35 & -0.08 & -1.15 & 0.14 & 3.44 & -0.06 & -5.18 & 0.02 & 0.71 & -0.36 & -10.73 & -0.07 & -2.09 & -0.02 & -0.45 & 0.18 & 0.14 & 0.11 & 0.00 \\
\hline & & $\begin{array}{l}2036- \\
2065\end{array}$ & -0.17 & -0.04 & 0.16 & 0.06 & 0.22 & 1.00 & 0.24 & 4.36 & 0.05 & 1.27 & -0.14 & -4.66 & 0.08 & 1.46 & 0.01 & 0.22 & 0.05 & 1.57 & -0.04 & -1.42 & 0.08 & 0.08 & 0.08 & 0.00 \\
\hline & & $\begin{array}{r}2066- \\
2095 \\
\end{array}$ & -0.09 & -0.02 & -0.09 & 0.00 & 0.05 & 0.17 & 0.03 & 0.66 & -0.20 & -4.46 & -0.20 & -9.31 & -0.03 & -1.52 & 0.08 & 2.37 & -0.06 & -1.52 & 0.24 & 2.79 & -0.32 & -0.56 & -0.01 & 0.00 \\
\hline & \multirow{3}{*}{ RCP 8.5} & $\begin{array}{l}2006- \\
2035\end{array}$ & 0.13 & 0.05 & -0.02 & 0.00 & 0.13 & 0.66 & -0.09 & -1.83 & 0.01 & 0.21 & 0.05 & 1.28 & -0.04 & -0.95 & -0.21 & -7.03 & -0.04 & -0.92 & -0.12 & -1.12 & -0.24 & -0.31 & -0.05 & 0.00 \\
\hline & & $\begin{array}{l}2036- \\
2065\end{array}$ & -0.06 & 0.00 & -0.12 & 0.00 & -0.03 & -0.15 & 0.13 & 2.47 & -0.14 & -4.01 & -0.16 & -5.80 & -0.03 & -0.66 & 0.10 & 2.84 & 0.05 & 0.87 & 0.24 & 3.05 & 0.02 & 0.02 & 0.18 & 0.00 \\
\hline & & $\begin{array}{l}2066- \\
2095 \\
\end{array}$ & -0.20 & -0.05 & -0.08 & 0.00 & -0.10 & -0.57 & -0.16 & -3.71 & 0.03 & 0.53 & -0.09 & -3.19 & 0.02 & 0.81 & 0.10 & 3.78 & -0.10 & -2.34 & -0.21 & -1.96 & -0.02 & -0.05 & -0.05 & 0.00 \\
\hline \multirow{5}{*}{ SB 3} & \multirow{2}{*}{ Historical } & $\begin{array}{l}1950- \\
1977\end{array}$ & 0.22 & 0.00 & -0.06 & 0.00 & -0.09 & -0.17 & -0.03 & -0.14 & -0.10 & -1.04 & -0.17 & -6.24 & -0.14 & -4.97 & -0.06 & -1.32 & -0.16 & -2.65 & -0.03 & -0.19 & -0.01 & 0.00 & 0.05 & 0.00 \\
\hline & & $\begin{array}{l}1978- \\
2005 \\
\end{array}$ & -0.11 & -0.02 & 0.11 & 0.01 & 0.04 & 0.07 & 0.04 & 0.20 & 0.06 & 1.80 & -0.07 & -1.95 & 0.04 & 0.81 & -0.22 & -5.82 & 0.06 & .43 & -0.12 & -0.89 & 0.15 & 0.06 & -0.05 & 0.00 \\
\hline & & $\begin{array}{l}2006- \\
2035\end{array}$ & 0.06 & 0.00 & -0.14 & -0.01 & -0.10 & -0.17 & -0.08 & -0.63 & 0.07 & 1.55 & -0.09 & -4.12 & 0.01 & 0.41 & -0.34 & -9.04 & -0.04 & -0.87 & -0.04 & -0.44 & 0.15 & 0.09 & -0.10 & 0.00 \\
\hline & RCP 4.5 & $\begin{array}{l}2036- \\
2065\end{array}$ & -0.06 & 0.00 & 0.08 & 0.00 & 0.22 & 0.51 & 0.25 & 3.86 & 0.07 & 1.55 & -0.15 & -4.24 & 0.05 & 1.51 & 0.00 & 0.11 & 0.04 & 0.96 & -0.08 & -0.96 & 0.09 & 0.06 & 0.11 & 0.00 \\
\hline & & $\begin{array}{r}2066- \\
2095 \\
\end{array}$ & -0.13 & 0.00 & -0.05 & 0.00 & 0.09 & 0.16 & 0.03 & 0.68 & -0.18 & -3.55 & -0.24 & -8.15 & -0.05 & -1.45 & 0.09 & 3.02 & -0.03 & -1.09 & 0.25 & 2.12 & $\mathbf{- 0 . 3 3}$ & -0.35 & -0.02 & 0.00 \\
\hline
\end{tabular}




\begin{tabular}{|c|c|c|c|c|c|c|c|c|c|c|c|c|c|c|c|c|c|c|c|c|c|c|c|c|c|}
\hline \multirow{3}{*}{ RCP 8.5} & $\begin{array}{l}2006- \\
2035\end{array}$ & 0.05 & 0.00 & 0.10 & 0.00 & 0.14 & 0.40 & -0.10 & -1.28 & 0.00 & 0.07 & 0.00 & 0.05 & -0.07 & -1.63 & -0.19 & -5.94 & -0.03 & -0.37 & -0.10 & -0.64 & -0.20 & -0.16 & -0.05 & 0.00 \\
\hline & $\begin{array}{l}2036- \\
2065\end{array}$ & -0.11 & 0.00 & -0.04 & 0.00 & -0.06 & -0.13 & 0.12 & 2.30 & -0.13 & -2.39 & -0.16 & -4.05 & -0.03 & -0.59 & 0.11 & 1.91 & 0.06 & 0.95 & 0.23 & 2.31 & 0.00 & 0.00 & 0.28 & 0.00 \\
\hline & $\begin{array}{l}2066- \\
2095\end{array}$ & -0.19 & 0.00 & -0.10 & 0.00 & -0.10 & -0.41 & -0.17 & -3.56 & 0.04 & 0.61 & -0.07 & -1.97 & 0.03 & 1.41 & 0.11 & 2.95 & -0.07 & -1.72 & -0.18 & -1.40 & -0.02 & 0.00 & -0.02 & 0.00 \\
\hline
\end{tabular}

Bold numbers show a significant trend at a $95 \%$ confidence level. 
Table 6. Mann-Kendall test Z-statistics and Sen's slope ( ${ }^{\circ} \mathrm{C} /$ year) for the study points (sub-basin level) of mean annual and seasonal T_max for historical (1950-2005) and futuristic (2006-2095) with RCP 4.5 and RCP 8.5 scenarios.

\begin{tabular}{|c|c|c|c|c|c|c|c|c|c|c|c|c|}
\hline \multirow{2}{*}{ Station } & \multirow{2}{*}{\multicolumn{2}{|c|}{ Time Scale/Seasons }} & \multicolumn{2}{|c|}{ Annual } & \multicolumn{2}{|c|}{ Winter } & \multicolumn{2}{|c|}{ Summer } & \multicolumn{2}{|c|}{ Monsoon } & \multicolumn{2}{|c|}{ Post-Monsoon } \\
\hline & & & $\mathbf{Z}$ & Slope & $\mathbf{Z}$ & Slope & $\mathbf{Z}$ & Slope & $\mathbf{Z}$ & Slope & $\mathbf{Z}$ & Slope \\
\hline \multirow{8}{*}{ SB 1} & \multirow{2}{*}{ Historical } & 1950-1977 & -0.360 & -0.041 & -0.196 & -0.060 & -0.217 & -0.048 & -0.540 & -0.029 & -0.228 & -0.033 \\
\hline & & $1978-2005$ & 0.275 & 0.029 & 0.212 & 0.060 & 0.249 & 0.059 & 0.169 & 0.013 & 0.228 & 0.038 \\
\hline & \multirow{3}{*}{ RCP 4.5} & $2006-2035$ & 0.467 & 0.053 & 0.237 & 0.050 & 0.232 & 0.055 & 0.669 & 0.046 & 0.434 & 0.054 \\
\hline & & $2036-2065$ & 0.402 & 0.042 & 0.246 & 0.080 & 0.122 & 0.022 & 0.618 & 0.043 & 0.476 & 0.055 \\
\hline & & 2066-2095 & 0.177 & 0.015 & 0.053 & 0.004 & 0.255 & 0.028 & 0.136 & 0.007 & 0.136 & 0.016 \\
\hline & \multirow{3}{*}{ RCP 8.5} & $2006-2035$ & 0.536 & 0.067 & 0.315 & 0.099 & 0.356 & 0.068 & 0.563 & 0.049 & 0.411 & 0.053 \\
\hline & & $2036-2065$ & 0.646 & 0.063 & 0.269 & 0.048 & 0.241 & 0.041 & 0.720 & 0.066 & 0.591 & 0.075 \\
\hline & & 2066-2099 & 0.664 & 0.095 & 0.338 & 0.084 & 0.646 & 0.151 & 0.692 & 0.060 & 0.485 & 0.057 \\
\hline \multirow{8}{*}{ SB 2} & \multirow{2}{*}{ Historical } & $1950-1977$ & -0.365 & -0.040 & -0.190 & -0.060 & -0.201 & -0.044 & -0.582 & -0.029 & -0.201 & -0.031 \\
\hline & & $1978-2005$ & 0.254 & 0.030 & 0.190 & 0.060 & 0.249 & 0.061 & 0.122 & 0.012 & 0.249 & 0.041 \\
\hline & \multirow{3}{*}{ RCP 4.5} & $2006-2035$ & 0.434 & 0.046 & 0.218 & 0.044 & 0.223 & 0.047 & 0.623 & 0.040 & 0.453 & 0.050 \\
\hline & & 2036-2065 & 0.329 & 0.038 & 0.251 & 0.068 & 0.099 & 0.013 & 0.605 & 0.041 & 0.439 & 0.051 \\
\hline & & 2066-2099 & 0.168 & 0.014 & 0.030 & 0.008 & 0.264 & 0.025 & 0.117 & 0.006 & 0.159 & 0.016 \\
\hline & \multirow{3}{*}{ RCP 8.5} & $2006-2035$ & 0.522 & 0.067 & 0.324 & 0.104 & 0.356 & 0.069 & 0.536 & 0.045 & 0.384 & 0.046 \\
\hline & & $2036-2065$ & 0.591 & 0.057 & 0.205 & 0.040 & 0.177 & 0.026 & 0.651 & 0.061 & 0.582 & 0.068 \\
\hline & & 2066-2099 & 0.660 & 0.097 & 0.338 & 0.085 & 0.628 & 0.161 & 0.687 & 0.059 & 0.444 & 0.056 \\
\hline \multirow{8}{*}{ SB 3} & \multirow{2}{*}{ Historical } & $1950-1977$ & -0.349 & -0.042 & -0.190 & -0.055 & -0.222 & -0.044 & -0.561 & -0.030 & -0.228 & -0.033 \\
\hline & & 1978-2005 & 0.249 & 0.027 & 0.196 & 0.059 & 0.238 & 0.062 & 0.153 & 0.015 & 0.228 & 0.041 \\
\hline & \multirow{3}{*}{ RCP 4.5} & $2006-2035$ & 0.462 & 0.053 & 0.237 & 0.050 & 0.232 & 0.058 & 0.674 & 0.046 & 0.444 & 0.056 \\
\hline & & $2036-2065$ & 0.352 & 0.039 & 0.246 & 0.073 & 0.094 & 0.016 & 0.614 & 0.042 & 0.462 & 0.052 \\
\hline & & 2066-2099 & 0.182 & 0.015 & 0.025 & 0.006 & 0.264 & 0.026 & 0.140 & 0.008 & 0.131 & 0.015 \\
\hline & \multirow{3}{*}{ RCP 8.5} & $2006-2035$ & 0.545 & 0.068 & 0.320 & 0.101 & 0.356 & 0.073 & 0.559 & 0.048 & 0.434 & 0.052 \\
\hline & & $2036-2065$ & 0.618 & 0.060 & 0.237 & 0.044 & 0.205 & 0.034 & 0.710 & 0.065 & 0.591 & 0.072 \\
\hline & & 2066-2099 & 0.674 & 0.095 & 0.329 & 0.081 & 0.628 & 0.159 & 0.706 & 0.061 & 0.485 & 0.056 \\
\hline
\end{tabular}

Bold numbers show a significant trend at 95\% confidence level. 
Table 7. Mann-Kendall test Z-statistics and Sen's slope ( ${ }^{\circ} \mathrm{C} /$ year) for the study points (sub-basin level) of mean monthly T_max for historical (1950-2005) and futuristic

(2006-2095) with RCP 4.5 and RCP 8.5 scenarios.

\begin{tabular}{|c|c|c|c|c|c|c|c|c|c|c|c|c|c|c|c|c|c|c|c|c|c|c|c|c|c|c|}
\hline \multirow{2}{*}{ Station } & \multirow{2}{*}{\multicolumn{2}{|c|}{ Time Scale/Months }} & \multirow{2}{*}{\multicolumn{2}{|c|}{ 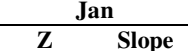 }} & \multicolumn{2}{|c|}{ Feb } & \multicolumn{2}{|c|}{ Mar } & \multicolumn{2}{|c|}{ Apr } & \multicolumn{2}{|c|}{ May } & \multicolumn{2}{|c|}{ Jun } & \multicolumn{2}{|c|}{ Jul } & \multicolumn{2}{|c|}{ Aug } & \multicolumn{2}{|c|}{ Sep } & \multicolumn{2}{|c|}{ Oct } & \multicolumn{2}{|c|}{ Nov } & \multicolumn{2}{|c|}{ Dec } \\
\hline & & & & & $\mathbf{Z}$ & Slope & $\mathbf{Z}$ & Slope & $\mathbf{Z}$ & Slope & $\mathbf{Z}$ & Slope & $\mathbf{Z}$ & Slope & $\mathbf{Z}$ & Slope & $\mathbf{Z}$ & Slope & $\mathbf{Z}$ & Slope & $\mathbf{Z}$ & Slope & $\mathbf{Z}$ & Slope & $\mathbf{Z}$ & Slope \\
\hline \multirow{8}{*}{ SB 1} & \multirow[t]{2}{*}{ Historical } & $\begin{array}{c}1950- \\
1977 \\
1978-\end{array}$ & -0.312 & -0.086 & -0.185 & -0.100 & -0.222 & -0.049 & -0.185 & -0.040 & -0.243 & -0.043 & -0.265 & -0.029 & -0.376 & -0.036 & -0.455 & -0.040 & -0.365 & -0.034 & -0.175 & -0.034 & -0.090 & -0.017 & -0.148 & -0.031 \\
\hline & & 2005 & 0.275 & 0.089 & 0.000 & -0.002 & 0.132 & 0.037 & 0.217 & 0.080 & 0.238 & 0.046 & 0.201 & 0.023 & 0.153 & 0.017 & 0.190 & 0.022 & 0.175 & 0.020 & 0.180 & 0.032 & 0.175 & 0.033 & 0.153 & 0.020 \\
\hline & \multirow{3}{*}{ RCP 4.5} & $\begin{array}{l}2006- \\
2035 \\
2036-\end{array}$ & 0.324 & 0.054 & 0.218 & 0.094 & 0.223 & 0.050 & 0.177 & 0.038 & 0.310 & 0.053 & 0.457 & 0.034 & 0.439 & 0.038 & 0.503 & 0.044 & 0.549 & 0.062 & 0.393 & 0.058 & 0.315 & 0.051 & 0.113 & 0.025 \\
\hline & & 2065 & -0.067 & -0.009 & 0.246 & 0.092 & 0.145 & 0.046 & -0.094 & -0.023 & 0.283 & 0.056 & 0.467 & 0.054 & 0.439 & 0.034 & 0.416 & 0.041 & 0.411 & 0.052 & 0.471 & 0.052 & 0.416 & 0.049 & 0.384 & 0.080 \\
\hline & & 2095 & -0.126 & -0.020 & 0.011 & 0.001 & -0.080 & -0.019 & 0.090 & 0.020 & 0.480 & 0.079 & 0.301 & 0.024 & 0.030 & 0.002 & -0.007 & 0.000 & -0.016 & -0.002 & 0.034 & 0.002 & 0.136 & 0.021 & 0.016 & 0.003 \\
\hline & \multirow{3}{*}{ RCP 8.5} & $\begin{array}{c}2006- \\
2035 \\
2036-\end{array}$ & 0.347 & 0.080 & 0.237 & 0.116 & 0.324 & 0.091 & 0.292 & 0.064 & 0.292 & 0.050 & 0.407 & 0.048 & 0.526 & 0.044 & 0.568 & 0.066 & 0.389 & 0.047 & 0.260 & 0.040 & 0.375 & 0.066 & 0.416 & 0.077 \\
\hline & & 2065 & 0.103 & 0.026 & 0.113 & 0.026 & 0.149 & 0.028 & 0.264 & 0.052 & 0.140 & 0.027 & 0.591 & 0.076 & 0.669 & 0.060 & 0.595 & 0.053 & 0.577 & 0.081 & 0.476 & 0.088 & 0.425 & 0.066 & 0.320 & 0.080 \\
\hline & & 2099 & 0.361 & 0.096 & 0.186 & 0.105 & 0.503 & 0.187 & 0.536 & 0.196 & 0.563 & 0.095 & 0.467 & 0.047 & 0.577 & 0.060 & 0.651 & 0.061 & 0.572 & 0.083 & 0.444 & 0.057 & 0.490 & 0.058 & 0.251 & 0.062 \\
\hline \multirow{8}{*}{ SB 2} & \multirow[t]{2}{*}{ Historical } & $\begin{array}{l}1950- \\
1977 \\
1978-\end{array}$ & -0.307 & -0.091 & -0.169 & -0.080 & -0.222 & -0.045 & -0.169 & -0.036 & -0.228 & -0.044 & -0.228 & -0.026 & -0.376 & -0.037 & -0.497 & -0.039 & -0.365 & -0.034 & -0.148 & -0.034 & -0.101 & -0.016 & -0.143 & -0.034 \\
\hline & & 2005 & 0.280 & 0.090 & -0.026 & -0.012 & 0.175 & 0.040 & 0.243 & 0.079 & 0.228 & 0.044 & 0.116 & 0.014 & 0.090 & 0.009 & 0.185 & 0.024 & 0.196 & 0.025 & 0.201 & 0.033 & 0.164 & 0.034 & 0.201 & 0.032 \\
\hline & \multirow{3}{*}{ RCP 4.5} & $\begin{array}{l}2006- \\
2035\end{array}$ & 0.264 & 0.045 & 0.228 & 0.088 & 0.195 & 0.053 & 0.145 & 0.042 & 0.274 & 0.048 & 0.398 & 0.029 & 0.379 & 0.034 & 0.485 & 0.041 & 0.540 & 0.059 & 0.379 & 0.057 & 0.352 & 0.046 & 0.090 & 0.019 \\
\hline & & $\begin{array}{c}2036- \\
2065 \\
2066-\end{array}$ & -0.108 & -0.024 & 0.232 & 0.081 & 0.113 & 0.034 & -0.103 & -0.027 & 0.251 & 0.050 & 0.430 & 0.049 & 0.416 & 0.030 & 0.425 & 0.043 & 0.370 & 0.049 & 0.448 & 0.052 & 0.356 & 0.041 & 0.389 & 0.070 \\
\hline & & 2099 & -0.117 & -0.019 & 0.016 & 0.012 & -0.085 & -0.018 & 0.108 & 0.021 & 0.462 & 0.081 & 0.260 & 0.023 & 0.030 & 0.002 & 0.002 & 0.000 & -0.048 & -0.004 & 0.016 & 0.002 & 0.140 & 0.019 & -0.002 & 0.000 \\
\hline & \multirow{3}{*}{ RCP 8.5} & $\begin{array}{l}2006- \\
2035 \\
2036-\end{array}$ & 0.324 & 0.079 & 0.255 & 0.118 & 0.329 & 0.094 & 0.297 & 0.066 & 0.297 & 0.048 & 0.343 & 0.036 & 0.513 & 0.042 & 0.554 & 0.065 & 0.370 & 0.044 & .218 & .038 & 0.352 & 0.059 & 0.370 & 0.072 \\
\hline & & $\begin{array}{c}2065 \\
2066-\end{array}$ & 0.053 & 0.014 & 0.085 & 0.028 & 0.108 & 0.019 & 0.191 & 0.052 & 0.080 & 0.015 & 0.536 & 0.070 & 0.632 & 0.054 & 0.563 & 0.052 & 0.536 & 0.077 & 0.448 & 0.087 & 0.379 & 0.054 & 0.306 & 0.077 \\
\hline & & 2099 & 0.430 & 0.106 & 0.137 & 0.079 & 0.458 & 0.148 & 0.544 & 0.184 & 0.633 & 0.107 & 0.462 & 0.044 & 0.619 & 0.062 & 0.668 & 0.060 & 0.579 & 0.075 & 0.430 & 0.060 & 0.565 & 0.075 & 0.312 & 0.071 \\
\hline \multirow{8}{*}{ SB 3} & Historical & $\begin{array}{l}1950- \\
1977\end{array}$ & -0.302 & -0.086 & -0.190 & -0.093 & -0.228 & -0.047 & -0.175 & -0.040 & -0.243 & -0.046 & -0.249 & -0.033 & -0.381 & -0.041 & -0.476 & -0.039 & -0.370 & -0.035 & -0.180 & -0.037 & -0.090 & -0.016 & -0.153 & -0.030 \\
\hline & Histontad & $\begin{array}{l}1978- \\
2005\end{array}$ & 0.270 & 0.087 & -0.011 & -0.006 & 0.175 & 0.041 & 0.233 & 0.077 & 0.243 & 0.045 & 0.190 & 0.022 & 0.159 & 0.016 & 0.190 & 0.022 & 0.185 & 0.020 & 0.212 & 0.034 & 0.164 & 0.034 & 0.153 & 0.026 \\
\hline & & $\begin{array}{l}2006- \\
2035\end{array}$ & 0.333 & 0.058 & 0.223 & 0.097 & 0.228 & 0.056 & 0.177 & 0.042 & 0.329 & 0.056 & 0.457 & 0.034 & 0.421 & 0.037 & 0.494 & 0.043 & 0.549 & 0.062 & 0.398 & 0.058 & 0.343 & 0.052 & 0.113 & 0.026 \\
\hline & RCP 4.5 & $\begin{array}{l}2036- \\
2065\end{array}$ & -0.076 & -0.018 & 0.237 & 0.083 & 0.103 & 0.038 & -0.131 & -0.030 & 0.264 & 0.051 & 0.434 & 0.054 & 0.434 & 0.033 & 0.421 & 0.040 & 0.398 & 0.052 & 0.476 & 0.053 & 0.343 & 0.043 & 0.389 & 0.078 \\
\hline & & $\begin{array}{r}2066- \\
2099 \\
\end{array}$ & -0.131 & -0.021 & 0.007 & 0.002 & -0.085 & -0.021 & 0.108 & 0.018 & 0.471 & 0.079 & 0.269 & 0.023 & 0.030 & 0.001 & -0.007 & 0.000 & -0.021 & -0.002 & 0.021 & 0.001 & 0.126 & 0.020 & 0.021 & 0.003 \\
\hline & & $\begin{array}{l}2006- \\
2035\end{array}$ & 0.352 & 0.077 & 0.241 & 0.116 & 0.343 & 0.094 & 0.306 & 0.064 & 0.310 & 0.053 & 0.389 & 0.046 & 0.526 & 0.045 & 0.577 & 0.067 & 0.407 & 0.046 & 0.255 & 0.042 & 0.384 & 0.066 & 0.402 & 0.081 \\
\hline & RCP 8.5 & $\begin{array}{l}2036- \\
2065\end{array}$ & 0.076 & 0.022 & 0.094 & 0.028 & 0.140 & 0.023 & 0.246 & 0.049 & 0.136 & 0.027 & 0.559 & 0.075 & 0.655 & 0.059 & 0.591 & 0.053 & 0.563 & 0.083 & 0.476 & 0.087 & 0.416 & 0.063 & 0.320 & 0.078 \\
\hline & & $\begin{array}{c}2066- \\
2099\end{array}$ & 0.419 & 0.104 & 0.141 & 0.076 & 0.462 & 0.143 & 0.540 & 0.168 & 0.622 & 0.106 & 0.444 & 0.042 & 0.633 & 0.063 & 0.683 & 0.062 & 0.586 & 0.075 & 0.487 & 0.063 & 0.572 & 0.070 & 0.319 & 0.072 \\
\hline
\end{tabular}

Bold numbers show a significant trend at a $95 \%$ confidence level. 
Table 8. Mann-Kendall test Z-statistics and Sen's slope ( ${ }^{\circ} \mathrm{C} /$ year) for the study points (sub-basin level) of mean annual T_min for historical (1950-2005) and futuristic (2006-2095) with RCP 4.5 and RCP 8.5 scenarios.

\begin{tabular}{|c|c|c|c|c|c|c|c|c|c|c|c|c|c|c|c|c|c|c|c|c|c|c|c|c|c|c|}
\hline \multirow{2}{*}{ Station } & \multirow{2}{*}{\multicolumn{2}{|c|}{$\begin{array}{c}\text { Time Scale } \\
\text { /Months }\end{array}$}} & \multirow{2}{*}{\multicolumn{2}{|c|}{\begin{tabular}{ll}
\multicolumn{2}{|c|}{ Jan } \\
$\mathrm{Z}$ & Slope
\end{tabular}}} & \multirow{2}{*}{\multicolumn{2}{|c|}{\begin{tabular}{ll}
\multicolumn{2}{|c}{ Feb } \\
$\mathrm{Z}$ & Slope
\end{tabular}}} & \multicolumn{2}{|c|}{ Mar } & \multicolumn{2}{|c|}{ Apr } & \multicolumn{2}{|c|}{ May } & \multicolumn{2}{|c|}{ Jun } & \multicolumn{2}{|c|}{ Jul } & \multicolumn{2}{|c|}{ Aug } & \multicolumn{2}{|c|}{ Sep } & \multicolumn{2}{|c|}{ Oct } & \multicolumn{2}{|c|}{ Nov } & \multicolumn{2}{|c|}{ Dec } \\
\hline & & & & & & Slope & $\mathbf{Z}$ & Slope & $\mathbf{Z}$ & Slope & $\mathbf{Z}$ & Slope & $\mathbf{Z}$ & Slope & $\mathbf{Z}$ & Slope & $\mathbf{Z}$ & Slope & $\mathbf{Z}$ & Slope & $\mathbf{Z}$ & Slope & $\mathbf{Z}$ & Slope & $\mathbf{Z}$ & Slope \\
\hline \multirow{8}{*}{ SB 1} & \multirow{2}{*}{ Historical } & $\begin{array}{l}1950- \\
1977\end{array}$ & -0.238 & -0.058 & -0.095 & -0.039 & -0.138 & -0.031 & -0.037 & -0.008 & -0.005 & -0.001 & -0.153 & -0.024 & -0.212 & -0.017 & -0.085 & -0.008 & -0.069 & -0.010 & -0.143 & -0.047 & -0.063 & -0.020 & 0.101 & 0.045 \\
\hline & & $\begin{array}{l}1978- \\
2005 \\
\end{array}$ & 0.169 & 0.032 & 0.048 & 0.025 & 0.053 & 0.010 & 0.206 & 0.042 & 0.190 & 0.027 & 0.286 & 0.043 & 0.286 & 0.026 & 0.180 & 0.018 & -0.058 & -0.008 & 0.212 & 0.045 & 0.138 & 0.034 & 0.021 & 0.008 \\
\hline & \multirow{3}{*}{ RCP 4.5} & $\begin{array}{l}2006- \\
2035\end{array}$ & 0.393 & 0.085 & 0.228 & 0.069 & 0.389 & 0.066 & 0.195 & 0.034 & 0.559 & 0.092 & 0.595 & 0.078 & 0.568 & 0.047 & 0.361 & 0.030 & 0.490 & 0.046 & 0.338 & 0.065 & 0.315 & 0.066 & 0.191 & 0.047 \\
\hline & & $\begin{array}{l}2036- \\
2065\end{array}$ & 0.034 & 0.011 & 0.159 & 0.067 & 0.149 & 0.034 & -0.214 & -0.037 & 0.324 & 0.037 & 0.517 & 0.043 & 0.499 & 0.032 & 0.453 & 0.043 & 0.411 & 0.044 & 0.430 & 0.079 & 0.209 & 0.047 & 0.338 & 0.084 \\
\hline & & $\begin{array}{l}2066- \\
2095 \\
\end{array}$ & 0.264 & 0.043 & -0.021 & -0.005 & 0.076 & 0.013 & 0.062 & 0.019 & 0.356 & 0.057 & 0.333 & 0.024 & 0.172 & 0.012 & -0.076 & -0.005 & 0.310 & 0.029 & -0.136 & -0.026 & 0.044 & 0.006 & 0.103 & 0.020 \\
\hline & \multirow{3}{*}{ RCP 8.5} & $\begin{array}{l}2006- \\
2035\end{array}$ & 0.228 & 0.058 & 0.246 & 0.091 & 0.246 & 0.047 & 0.274 & 0.047 & 0.508 & 0.078 & 0.568 & 0.071 & 0.683 & 0.050 & 0.494 & 0.046 & 0.476 & 0.069 & 0.154 & 0.032 & 0.448 & 0.050 & 0.398 & 0.077 \\
\hline & & $\begin{array}{l}2036- \\
2065\end{array}$ & 0.287 & 0.067 & 0.182 & 0.067 & 0.320 & 0.063 & 0.434 & 0.080 & 0.393 & 0.078 & 0.669 & 0.085 & 0.618 & 0.059 & 0.660 & 0.067 & 0.710 & 0.084 & 0.384 & 0.083 & 0.623 & 0.115 & 0.586 & 0.130 \\
\hline & & $\begin{array}{l}2066- \\
2095 \\
\end{array}$ & 0.241 & 0.066 & 0.232 & 0.087 & 0.577 & 0.144 & 0.623 & 0.130 & 0.651 & 0.114 & 0.646 & 0.057 & 0.660 & 0.063 & 0.609 & 0.052 & 0.609 & 0.067 & 0.370 & 0.078 & 0.421 & 0.057 & 0.389 & 0.093 \\
\hline \multirow{8}{*}{ SB 2} & \multirow{2}{*}{ Historical } & $\begin{array}{l}1950- \\
1977\end{array}$ & -0.233 & -0.048 & -0.026 & -0.009 & -0.090 & -0.018 & 0.016 & 0.003 & 0.000 & 0.000 & -0.143 & -0.023 & -0.228 & -0.017 & -0.122 & -0.009 & -0.069 & -0.008 & -0.159 & -0.052 & -0.111 & -0.021 & 0.148 & 0.061 \\
\hline & & $\begin{array}{l}1978- \\
2005 \\
\end{array}$ & 0.153 & 0.023 & 0.042 & 0.010 & 0.085 & 0.021 & 0.238 & 0.050 & 0.175 & 0.022 & 0.307 & 0.038 & 0.328 & 0.029 & 0.164 & 0.017 & -0.026 & -0.004 & 0.228 & 0.041 & 0.138 & 0.043 & 0.016 & 0.005 \\
\hline & \multirow{3}{*}{ RCP 4.5} & $\begin{array}{l}2006- \\
2035\end{array}$ & 0.287 & 0.065 & 0.356 & 0.089 & 0.306 & 0.051 & 0.159 & 0.023 & 0.549 & 0.088 & 0.614 & 0.070 & 0.600 & 0.045 & 0.416 & 0.031 & 0.499 & 0.045 & 0.324 & 0.068 & 0.361 & 0.070 & 0.232 & 0.060 \\
\hline & & $\begin{array}{l}2036- \\
2065\end{array}$ & -0.002 & 0.000 & 0.205 & 0.063 & 0.122 & 0.025 & -0.200 & -0.037 & 0.338 & 0.040 & 0.526 & 0.042 & 0.503 & 0.032 & 0.425 & 0.042 & 0.393 & 0.040 & 0.444 & 0.073 & 0.260 & 0.056 & 0.356 & 0.091 \\
\hline & & $\begin{array}{l}2066- \\
2095 \\
\end{array}$ & 0.310 & 0.064 & -0.007 & -0.005 & 0.094 & 0.015 & 0.080 & 0.013 & 0.379 & 0.059 & 0.310 & 0.022 & 0.177 & 0.011 & -0.099 & -0.007 & 0.301 & 0.029 & -0.131 & -0.026 & 0.071 & 0.013 & 0.149 & 0.026 \\
\hline & \multirow{3}{*}{ RCP 8.5} & $\begin{array}{l}2006- \\
2035\end{array}$ & 0.218 & 0.048 & 0.232 & 0.088 & 0.186 & 0.044 & 0.264 & 0.044 & 0.531 & 0.075 & 0.563 & 0.070 & 0.664 & 0.050 & 0.517 & 0.042 & 0.522 & 0.071 & 0.163 & 0.033 & 0.453 & 0.053 & 0.411 & 0.081 \\
\hline & & $\begin{array}{l}2036- \\
2065\end{array}$ & 0.269 & 0.058 & 0.218 & 0.077 & 0.320 & 0.065 & 0.448 & 0.084 & 0.384 & 0.075 & 0.706 & 0.079 & 0.618 & 0.059 & 0.651 & 0.062 & 0.683 & 0.081 & 0.370 & 0.082 & 0.646 & 0.112 & 0.586 & 0.138 \\
\hline & & $\begin{array}{r}2066- \\
2095 \\
\end{array}$ & 0.394 & 0.106 & 0.230 & 0.084 & 0.529 & 0.114 & 0.608 & 0.126 & 0.686 & 0.116 & 0.704 & 0.056 & 0.661 & 0.058 & 0.658 & 0.056 & 0.679 & 0.067 & 0.476 & .090 & .455 & 0.055 & .465 & 0.112 \\
\hline \multirow{8}{*}{ SB 3} & Histol & $\begin{array}{l}1950- \\
1977\end{array}$ & -0.249 & -0.051 & -0.079 & -0.040 & -0.127 & -0.029 & -0.032 & -0.004 & 0.005 & 0.001 & -0.153 & -0.024 & -0.196 & -0.017 & -0.079 & -0.008 & -0.085 & -0.009 & -0.153 & -0.048 & -0.069 & -0.007 & 0.122 & 0.047 \\
\hline & Hostontial & $\begin{array}{l}1978- \\
2005 \\
\end{array}$ & 0.159 & 0.029 & 0.058 & 0.026 & 0.058 & 0.011 & 0.217 & 0.042 & 0.164 & 0.021 & 0.280 & 0.043 & 0.312 & 0.028 & 0.180 & 0.018 & -0.053 & -0.007 & 0.212 & 0.042 & 0.116 & 0.036 & -0.005 & -0.001 \\
\hline & & $\begin{array}{l}2006- \\
2035\end{array}$ & 0.393 & 0.084 & 0.278 & 0.101 & 0.393 & 0.067 & 0.172 & 0.030 & 0.563 & 0.093 & 0.591 & 0.077 & 0.568 & 0.048 & 0.384 & 0.031 & 0.480 & 0.047 & 0.338 & 0.068 & 0.333 & 0.072 & 0.195 & 0.054 \\
\hline & RCP 4.5 & $\begin{array}{l}2036- \\
2065\end{array}$ & 0.039 & 0.011 & 0.168 & 0.066 & 0.149 & 0.034 & -0.223 & -0.036 & 0.306 & 0.037 & 0.522 & 0.043 & 0.476 & 0.030 & 0.430 & 0.043 & 0.398 & 0.043 & 0.439 & 0.080 & 0.223 & 0.049 & 0.320 & 0.084 \\
\hline & & $\begin{array}{l}2066- \\
2095 \\
\end{array}$ & 0.278 & 0.054 & -0.007 & -0.002 & 0.085 & 0.011 & 0.071 & 0.017 & 0.361 & 0.058 & 0.333 & 0.023 & 0.154 & 0.012 & -0.094 & -0.006 & 0.310 & 0.028 & -0.117 & -0.027 & 0.048 & 0.007 & 0.145 & 0.023 \\
\hline & & $\begin{array}{l}2006- \\
2035\end{array}$ & 0.237 & 0.052 & 0.241 & 0.091 & 0.241 & 0.045 & 0.283 & 0.046 & 0.517 & 0.080 & 0.577 & 0.074 & 0.678 & 0.051 & 0.494 & 0.045 & 0.499 & 0.070 & 0.154 & 0.033 & 0.434 & 0.051 & 0.407 & 0.082 \\
\hline & RCP 8.5 & $\begin{array}{l}2036- \\
2065\end{array}$ & 0.301 & 0.064 & 0.205 & 0.071 & 0.306 & 0.064 & 0.439 & 0.081 & 0.384 & 0.083 & 0.674 & 0.084 & 0.605 & 0.058 & 0.641 & 0.067 & 0.706 & 0.084 & 0.375 & 0.082 & 0.623 & 0.117 & 0.586 & 0.135 \\
\hline & & $\begin{array}{l}2066- \\
2095 \\
\end{array}$ & 0.405 & 0.114 & 0.234 & 0.087 & 0.576 & 0.120 & 0.626 & 0.126 & 0.683 & 0.116 & 0.693 & 0.056 & 0.693 & 0.061 & 0.679 & 0.056 & 0.640 & 0.070 & 0.487 & 0.093 & 0.472 & 0.059 & 0.476 & 0.118 \\
\hline
\end{tabular}

Bold numbers show a significant trend at a $95 \%$ confidence level. 
Table 9. Mann-Kendall test Z-statistics and Sen's slope ( ${ }^{\circ} \mathrm{C} /$ year) for the study points (sub-basin level) of mean annual and seasonal T_min for historical (1950-2005) and futuristic (2006-2095) with RCP 4.5 and RCP 8.5 scenarios.

\begin{tabular}{|c|c|c|c|c|c|c|c|c|c|c|c|c|}
\hline \multirow{2}{*}{ Station } & \multirow{2}{*}{\multicolumn{2}{|c|}{ Time Scale/Seasons }} & \multicolumn{2}{|c|}{ Annual } & \multicolumn{2}{|c|}{ Winter } & \multicolumn{2}{|c|}{ Summer } & \multicolumn{2}{|c|}{ Monsoon } & \multicolumn{2}{|c|}{ Post-Monsoon } \\
\hline & & & $\mathbf{Z}$ & Slope & $\mathbf{Z}$ & Slope & $\mathbf{Z}$ & Slope & $\mathbf{Z}$ & Slope & $\mathbf{Z}$ & Slope \\
\hline \multirow{8}{*}{ SB 1} & \multirow{2}{*}{ Historical } & 1950-1977 & -0.222 & -0.025 & -0.058 & -0.020 & -0.058 & -0.010 & -0.217 & -0.013 & -0.175 & -0.031 \\
\hline & & $1978-2005$ & 0.233 & 0.021 & 0.090 & 0.025 & 0.238 & 0.029 & 0.392 & 0.024 & $\mathbf{0 . 3 0 7}$ & 0.043 \\
\hline & \multirow{3}{*}{ RCP 4.5} & 2006-2035 & 0.545 & 0.060 & 0.278 & 0.054 & 0.444 & 0.062 & 0.614 & 0.054 & 0.457 & 0.064 \\
\hline & & $2036-2065$ & 0.462 & 0.036 & 0.195 & 0.048 & 0.085 & 0.005 & 0.605 & 0.042 & 0.471 & 0.071 \\
\hline & & $2066-2095$ & 0.246 & 0.023 & 0.126 & 0.025 & 0.182 & 0.025 & 0.343 & 0.017 & -0.025 & -0.004 \\
\hline & \multirow{3}{*}{ RCP 8.5} & $2006-2035$ & 0.591 & 0.059 & 0.320 & 0.070 & 0.490 & 0.051 & 0.738 & 0.062 & 0.352 & 0.039 \\
\hline & & $2036-2065$ & 0.738 & 0.080 & 0.366 & 0.084 & 0.499 & 0.078 & 0.834 & 0.073 & 0.646 & 0.105 \\
\hline & & 2066-2099 & 0.669 & 0.090 & 0.338 & 0.093 & 0.747 & 0.137 & 0.766 & 0.063 & 0.503 & 0.062 \\
\hline \multirow{8}{*}{ SB 2} & \multirow{2}{*}{ Historical } & 1950-1977 & -0.185 & -0.021 & 0.042 & 0.009 & -0.042 & -0.005 & -0.217 & -0.014 & -0.180 & -0.031 \\
\hline & & $1978-2005$ & 0.254 & 0.020 & 0.048 & 0.009 & 0.265 & 0.033 & 0.397 & 0.026 & 0.323 & 0.052 \\
\hline & \multirow{3}{*}{ RCP 4.5} & $2006-2035$ & 0.646 & 0.057 & 0.444 & 0.070 & 0.411 & 0.053 & 0.651 & 0.050 & 0.503 & 0.068 \\
\hline & & $2036-2065$ & 0.503 & 0.032 & 0.251 & 0.035 & 0.067 & 0.007 & 0.595 & 0.040 & 0.467 & 0.066 \\
\hline & & 2066-2099 & 0.260 & 0.024 & 0.177 & 0.033 & 0.223 & 0.031 & 0.356 & 0.017 & -0.011 & -0.002 \\
\hline & \multirow{3}{*}{ RCP 8.5} & $2006-2035$ & 0.568 & 0.059 & 0.292 & 0.069 & 0.434 & 0.052 & 0.738 & 0.060 & 0.343 & 0.042 \\
\hline & & $2036-2065$ & 0.701 & 0.079 & 0.361 & 0.091 & 0.494 & 0.077 & 0.830 & 0.068 & 0.628 & 0.104 \\
\hline & & 2066-2099 & 0.646 & 0.087 & 0.306 & 0.090 & $\mathbf{0 . 7 3 3}$ & 0.138 & 0.775 & 0.061 & 0.540 & 0.063 \\
\hline \multirow{8}{*}{ SB 3} & \multirow{2}{*}{ Historical } & 1950-1977 & -0.201 & -0.023 & -0.032 & -0.009 & -0.037 & -0.006 & -0.212 & -0.013 & -0.159 & -0.027 \\
\hline & & $1978-2005$ & 0.228 & 0.020 & 0.095 & 0.016 & 0.243 & 0.029 & 0.402 & 0.026 & 0.307 & 0.043 \\
\hline & \multirow{3}{*}{ RCP 4.5} & $2006-2035$ & 0.554 & 0.066 & 0.343 & 0.062 & 0.444 & 0.060 & 0.637 & 0.054 & 0.476 & 0.066 \\
\hline & & $2036-2065$ & 0.462 & 0.036 & 0.195 & 0.051 & 0.053 & 0.005 & 0.605 & 0.041 & 0.490 & 0.072 \\
\hline & & 2066-2099 & 0.246 & 0.023 & 0.149 & 0.030 & 0.209 & 0.026 & 0.333 & 0.018 & -0.016 & -0.001 \\
\hline & \multirow{3}{*}{ RCP 8.5} & 2006-2035 & 0.591 & 0.059 & 0.297 & 0.075 & 0.467 & 0.056 & 0.724 & 0.063 & 0.347 & 0.040 \\
\hline & & $2036-2065$ & 0.720 & 0.081 & 0.384 & 0.091 & 0.490 & 0.078 & 0.830 & 0.071 & 0.651 & 0.108 \\
\hline & & 2066-2099 & 0.664 & 0.090 & 0.329 & 0.090 & 0.733 & 0.137 & 0.761 & 0.062 & 0.522 & 0.065 \\
\hline
\end{tabular}

Bold numbers show a significant trend at a $95 \%$ confidence level. 
Table 10. Mann-Kendall test Z-statistics and Sen's slope $\left({ }^{\circ} \mathrm{C} /\right.$ year) for the study points (sub-basin level) of mean annual DTR for historical (1950-2005) and futuristic (2006-

2095) with RCP 4.5 and RCP 8.5 scenarios.

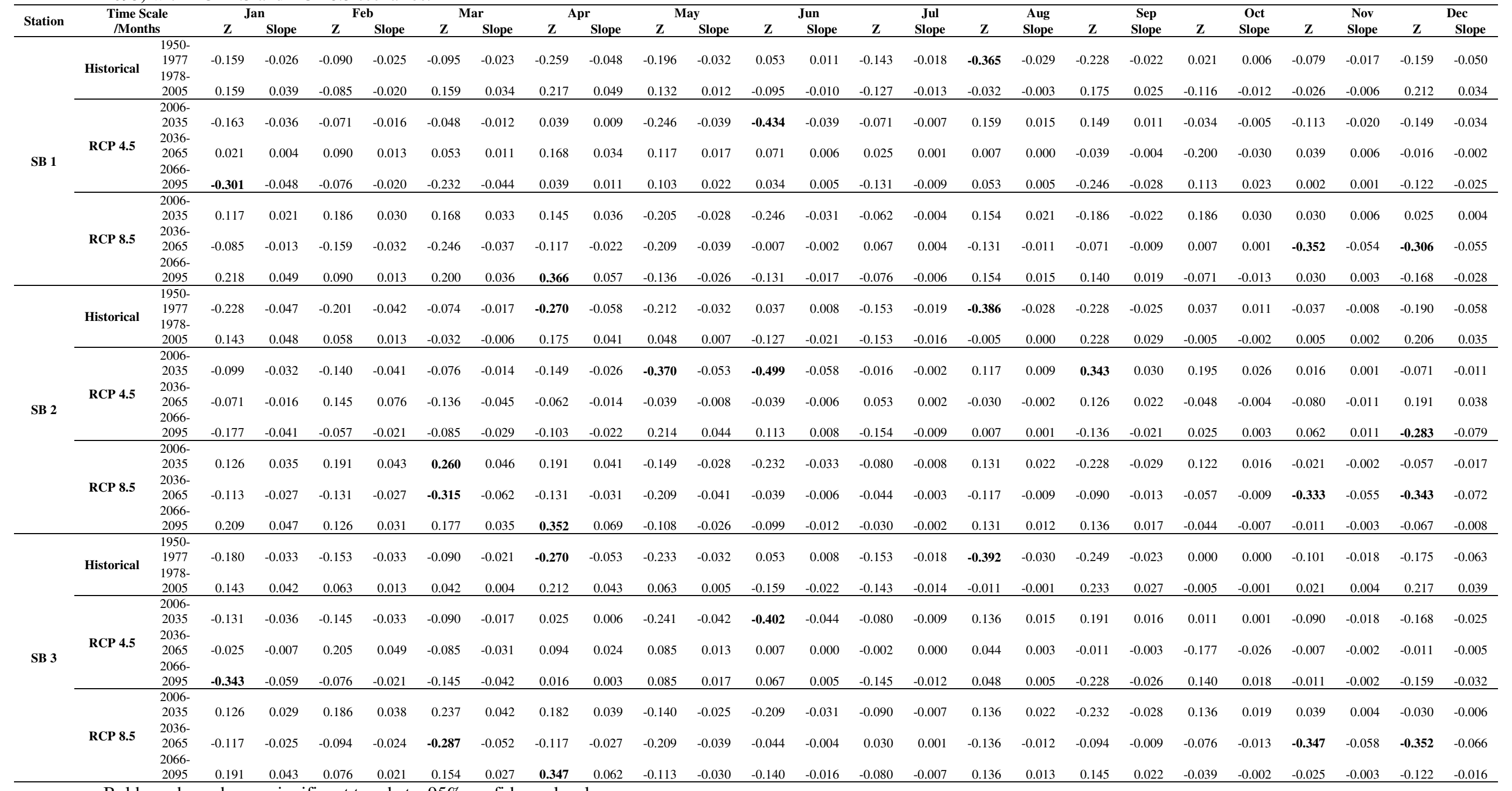

Bold numbers show a significant trend at a $95 \%$ confidence level. 
Table 11. Changepoint analysis of mean monthly and annual precipitation, T_min, and T_max over the three study points under historic, RCP4.5, and RCP8.5.

\begin{tabular}{|c|c|c|c|c|c|c|c|c|c|c|c|c|c|c|c|c|c|c|}
\hline \multirow{3}{*}{ Month } & \multicolumn{6}{|c|}{ Study Point 1} & \multicolumn{6}{|c|}{ Study Point 2} & \multirow{2}{*}{\multicolumn{4}{|c|}{$\begin{array}{c}\text { Study Point } 3 \\
\text { T_min }\end{array}$}} & \multirow{2}{*}{\multicolumn{2}{|c|}{ T_max }} \\
\hline & \multicolumn{2}{|c|}{ Precipitation } & \multicolumn{2}{|c|}{ T_min } & \multicolumn{2}{|l|}{ T_max } & \multicolumn{2}{|c|}{ Precipitation } & \multicolumn{2}{|c|}{ T_min } & \multicolumn{2}{|l|}{ T_max } & & & & & & \\
\hline & Change year & Shift & Change year & Shift & Change year & Shift & Change year & Shift & Change year & Shift & Change year & Shift & Change year & Shift & Change year & Shift & Change year & Shift \\
\hline January & 2038 (8.5) & $\downarrow$ & $\begin{array}{l}2033(4.5) \\
2055(8.5) \\
\end{array}$ & $\uparrow$ & $\begin{array}{l}2065(4.5) \\
2055(8.5) \\
\end{array}$ & $\uparrow$ & & & $\begin{array}{l}2033(4.5) \\
2051(8.5) \\
\end{array}$ & $\uparrow$ & $\begin{array}{l}2065(4.5) \\
2055(8.5) \\
\end{array}$ & $\uparrow$ & & & $\begin{array}{l}2033(4.5) \\
2055(8.5) \\
\end{array}$ & $\uparrow$ & $\begin{array}{l}2065(4.5) \\
2055(8.5) \\
\end{array}$ & $\uparrow$ \\
\hline February & & & $\begin{array}{l}2044(4.5) \\
2052(8.5)\end{array}$ & $\uparrow$ & $\begin{array}{l}2060(4.5) \\
2064(8.5)\end{array}$ & $\uparrow$ & & & $\begin{array}{l}1976 \text { (Hist) } \\
2043(4.5) \\
2052(8.5)\end{array}$ & $\uparrow$ & $\begin{array}{l}2060(4.5) \\
2064(8.5)\end{array}$ & $\uparrow$ & & & $\begin{array}{l}2044(4.5) \\
2052(8.5)\end{array}$ & $\uparrow$ & $\begin{array}{l}2060(4.5) \\
2064(8.5)\end{array}$ & $\uparrow$ \\
\hline March & & & $\begin{array}{l}2059(4.5) \\
2050(8.5)\end{array}$ & $\uparrow$ & $\begin{array}{l}2060(4.5) \\
2067(8.5)\end{array}$ & $\uparrow$ & & & $\begin{array}{l}2059(4.5) \\
2050(8.5)\end{array}$ & $\uparrow$ & $\begin{array}{l}2060(4.5) \\
2067(8.5)\end{array}$ & $\uparrow$ & & & $\begin{array}{l}2059(4.5) \\
2050(8.5)\end{array}$ & $\uparrow$ & $\begin{array}{l}2060(4.5) \\
2067(8.5)\end{array}$ & $\uparrow$ \\
\hline April & $2048(4.5)$ & $\uparrow$ & $\begin{array}{l}2035(4.5) \\
2051(8.5) \\
\end{array}$ & $\uparrow$ & $\begin{array}{l}2037(4.5) \\
2051(8.5) \\
\end{array}$ & $\uparrow$ & & & $\begin{array}{l}2035(4.5) \\
2051(8.5) \\
\end{array}$ & $\uparrow$ & $\begin{array}{l}2037(4.5) \\
2074(8.5) \\
\end{array}$ & $\uparrow$ & & & $\begin{array}{l}2035(4.5) \\
2051(8.5) \\
\end{array}$ & $\uparrow$ & $\begin{array}{l}2037(4.5) \\
2074(8.5) \\
\end{array}$ & $\uparrow$ \\
\hline May & & & $\begin{array}{l}2052(4.5) \\
2051(8.5) \\
\end{array}$ & $\uparrow$ & $\begin{array}{l}2052(4.5) \\
2051(8.5) \\
\end{array}$ & $\uparrow$ & & & $\begin{array}{l}2052(4.5) \\
2051(8.5) \\
\end{array}$ & $\uparrow$ & $\begin{array}{l}2054(4.5) \\
2051(8.5)\end{array}$ & $\uparrow$ & & & $\begin{array}{l}2052(4.5) \\
2051(8.5)\end{array}$ & $\uparrow$ & $\begin{array}{l}2052(4.5) \\
2051(8.5)\end{array}$ & $\uparrow$ \\
\hline June & & & $\begin{array}{l}2049(4.5) \\
2051(8.5)\end{array}$ & $\uparrow$ & $\begin{array}{l}2052(4.5) \\
2049(8.5)\end{array}$ & $\uparrow$ & & & $\begin{array}{l}2049(4.5) \\
2050(8.5)\end{array}$ & $\uparrow$ & $\begin{array}{l}2052(4.5) \\
2054(8.5)\end{array}$ & $\uparrow$ & & & $\begin{array}{l}2049(4.5) \\
2051(8.5)\end{array}$ & $\uparrow$ & $\begin{array}{l}2052(4.5) \\
2054(8.5)\end{array}$ & $\uparrow$ \\
\hline July & $2020(4.5)$ & $\downarrow$ & $\begin{array}{l}2051(4.5) \\
2052(8.5) \\
\end{array}$ & $\uparrow$ & $\begin{array}{l}2053(4.5) \\
2050(8.5) \\
\end{array}$ & $\uparrow$ & & & $\begin{array}{l}2051(4.5) \\
2052(8.5) \\
\end{array}$ & $\uparrow$ & $\begin{array}{l}2053(4.5) \\
2050(8.5) \\
\end{array}$ & $\uparrow$ & $2044(4.5)$ & $\uparrow$ & $\begin{array}{l}2051(4.5) \\
2052(8.5) \\
\end{array}$ & $\uparrow$ & $\begin{array}{l}2053(4.5) \\
2050(8.5) \\
\end{array}$ & $\uparrow$ \\
\hline August & $2049(8.5)$ & $\uparrow$ & $\begin{array}{l}2051(4.5) \\
2055(8.5) \\
\end{array}$ & $\uparrow$ & $\begin{array}{l}2048(4.5) \\
2049(8.5) \\
\end{array}$ & $\uparrow$ & $2049(8.5)$ & $\uparrow$ & $\begin{array}{l}2051(4.5) \\
2055(8.5) \\
\end{array}$ & $\uparrow$ & $\begin{array}{l}2048(4.5) \\
2054(8.5) \\
\end{array}$ & $\uparrow$ & & & $\begin{array}{l}2051(4.5) \\
2055(8.5) \\
\end{array}$ & $\uparrow$ & $\begin{array}{l}2048(4.5) \\
2054(8.5) \\
\end{array}$ & $\uparrow$ \\
\hline September & & & $\begin{array}{l}2047(4.5) \\
2048(8.5) \\
\end{array}$ & $\uparrow$ & $\begin{array}{l}2053(4.5) \\
2050(8.5) \\
\end{array}$ & $\uparrow$ & & & $\begin{array}{l}2047(4.5) \\
2050(8.5) \\
\end{array}$ & $\uparrow$ & $\begin{array}{l}2053(4.5) \\
2054(8.5) \\
\end{array}$ & $\uparrow$ & & & $\begin{array}{l}2047(4.5) \\
2048(8.5) \\
\end{array}$ & $\uparrow$ & $\begin{array}{l}2053(4.5) \\
2052(8.5) \\
\end{array}$ & $\uparrow$ \\
\hline October & $2059(8.5)$ & $\uparrow$ & $\begin{array}{l}2057(4.5) \\
2057(8.5) \\
\end{array}$ & $\uparrow$ & $\begin{array}{l}2051(4.5) \\
2052(8.5) \\
\end{array}$ & $\uparrow$ & $\begin{array}{l}1988 \text { (Hist) } \\
2056(8.5)\end{array}$ & $\begin{array}{l}\downarrow \downarrow \\
\uparrow\end{array}$ & $\begin{array}{l}2057(4.5) \\
2057(8.5) \\
\end{array}$ & $\uparrow$ & $\begin{array}{l}2051(4.5) \\
2052(8.5) \\
\end{array}$ & $\uparrow$ & $\begin{array}{l}1988 \text { (Hist) } \\
2059(8.5) \\
\end{array}$ & $\begin{array}{l}\downarrow \\
\uparrow\end{array}$ & $\begin{array}{l}2057(4.5) \\
2057(8.5) \\
\end{array}$ & $\uparrow$ & $\begin{array}{l}2051(4.5) \\
2052(8.5) \\
\end{array}$ & $\uparrow$ \\
\hline November & & & $\begin{array}{l}2051(4.5) \\
2049(8.5) \\
\end{array}$ & $\uparrow$ & $\begin{array}{l}2051(4.5) \\
2044(8.5) \\
\end{array}$ & $\uparrow$ & & & $\begin{array}{l}2051(4.5) \\
2052(8.5) \\
\end{array}$ & $\uparrow$ & $\begin{array}{l}2049(4.5) \\
2050(8.5) \\
\end{array}$ & $\uparrow$ & & & $\begin{array}{l}2051(4.5) \\
2049(8.5) \\
\end{array}$ & $\uparrow$ & $\begin{array}{l}2051(4.5) \\
2050(8.5) \\
\end{array}$ & $\uparrow$ \\
\hline December & & & $\begin{array}{l}2048(4.5) \\
2045(8.5) \\
\end{array}$ & $\uparrow$ & $\begin{array}{l}2048(4.5) \\
2054(8.5) \\
\end{array}$ & $\uparrow$ & & & $\begin{array}{l}2048(4.5) \\
2054(8.5) \\
\end{array}$ & $\uparrow$ & $\begin{array}{l}2048(4.5) \\
2054(8.5) \\
\end{array}$ & $\uparrow$ & & & $\begin{array}{l}2048(4.5) \\
2054(8.5) \\
\end{array}$ & $\uparrow$ & $\begin{array}{l}2048(4.5) \\
2054(8.5) \\
\end{array}$ & $\uparrow$ \\
\hline Annual & $2065(8.5)$ & $\uparrow$ & $\begin{array}{l}2052(4.5) \\
2052(8.5) \\
\end{array}$ & $\uparrow$ & $\begin{array}{l}1963 \text { (Hist) } \\
2049(4.5) \\
2050(8.5)\end{array}$ & $\begin{array}{l}\downarrow \\
\uparrow\end{array}$ & $2065(8.5)$ & $\uparrow$ & $\begin{array}{l}2052(4.5) \\
2052(8.5) \\
\end{array}$ & $\uparrow$ & $\begin{array}{l}1963 \text { (Hist) } \\
2049(4.5) \\
2054(8.5)\end{array}$ & $\begin{array}{l}\downarrow \\
\uparrow\end{array}$ & $2065(8.5)$ & $\uparrow$ & $\begin{array}{l}2052(4.5) \\
2052(8.5) \\
\end{array}$ & $\uparrow$ & $\begin{array}{l}1963 \text { (Hist) } \\
2049(4.5) \\
2054(8.5)\end{array}$ & $\begin{array}{l}\downarrow \\
\uparrow\end{array}$ \\
\hline
\end{tabular}

Sign $\uparrow$ showing increasing change point and sign $\downarrow$ showing decreasing change point 